\title{
Multiplicity among solar-type stars
}

\section{The CORAVEL radial velocities and the spectroscopic orbits of nearby K dwarfs ${ }^{\star, \star \star}$}

\author{
J.-L. Halbwachs ${ }^{1}$, M. Mayor ${ }^{2}$, and S. Udry ${ }^{2}$ \\ 1 Université de Strasbourg, CNRS, Observatoire Astronomique de Strasbourg, UMR 7550, 11, rue de l'Université, 67000 Strasbourg, \\ France \\ e-mail: jean-louis.halbwachs@astro.unistra.fr \\ 2 Observatoire Astronomique de l'Université de Genève, 51, chemin des Maillettes, 1290 Sauverny, Switzerland
}

Received 7 May 2018 / Accepted 2 August 2018

\begin{abstract}
Context. The statistical properties of binary stars are clues for understanding their formation process. A radial velocity survey was carried on amongst nearby G-type stars and the results were published in 1991.

Aims. The survey of radial velocity measurements was extended towards K-type stars.

Methods. A sample of $261 \mathrm{~K}$-type stars was observed with the spectrovelocimeter CORAVEL (COrrelation RAdial VELocities). Those stars with a variable radial velocity were detected on the basis of the $P\left(\chi^{2}\right)$ test. The orbital elements of the spectroscopic binaries were then derived.

Results. The statistical properties of binary stars were derived from these observations and published in 2003 . We present the catalogue of the radial velocity measurements obtained with CORAVEL for all the K stars of the survey and the orbital elements derived for 34 spectroscopic systems. In addition, the catalogue contains eight G-type spectroscopic binaries that have received additional measurements since 1991 and for which the orbital elements are revised or derived for the first time.
\end{abstract}

Key words. solar neighborhood - binaries: spectroscopic - stars: solar-type - stars: late-type

\section{Introduction}

The spectrovelocimeter CORAVEL (COrrelation RAdial VELocities; Baranne et al. 1979) was installed on the Swiss $1-\mathrm{m}$ telescope at the Observatory of Haute-Provence (OHP) from the late 1970s until its decommissioning in 2000. Amongst other programmes, it provided the radial-velocity (RV) measurements exploited in two statistical studies of binarity among the stars in the solar neighbourhood: the study of solar-type stars until G8, and its extension towards the K-type stars. A series of articles has been devoted to these programmes. The first (Duquennoy et al. 1991; Paper I hereafter) presented the radial-velocity measurements of the sample of F-G type stars; these data led to the orbital elements of several spectroscopic binaries (SBs), and to the statistical properties of solar-type binaries (Duquennoy \& Mayor 1991; DM91 hereafter). Later, Halbwachs et al. (2003; Paper III hereafter) extended the statistical investigations to the K-type binaries with periods shorter than ten years, again on the basis of CORAVEL observations. This paper presented the parameters relevant for statistics, namely the periods, the semi-amplitudes, the mass ratios, and the orbital eccentricities of the spectroscopic binaries, excluding the other orbital elements. The long period K-type binaries were eventually studied by Eggenberger et al. (2004).

\footnotetext{
$\star$ Based on photoelectric radial-velocity measurements collected at Haute-Provence Observatory.

$\star \star$ Tables A.1 and A.2 are also available at the CDS via anonymous ftp to cdsarc.u-strasbg.fr $(130.79 .128 .5)$ or via http:// cdsarc.u-strasbg.fr/viz-bin/qcat?J/A+A/619/A81
}

The present paper completes the series by presenting the radial velocity measurements and the full set of orbital elements that gave rise to Paper III. It will give the orbits we have discovered all the visibility they deserve, so that they are henceforth taken into account in statistical studies, such as that of Raghavan et al. (2010). Moreover, they will be available for the validation of the spectroscopic orbits derived from the Radial Velocity Spectrometer of the Gaia satellite (Gaia Collaboration 2016). The CORAVEL programme is presented in Sect. 2, the RV catalogue is in Sect. 3, and the spectroscopic orbital elements are in Sect. 4. Section 5 is the conclusion.

\section{The CORAVEL survey of nearby K-type stars}

The CORAVEL survey for nearby SBs was initiated in the early 1980s, although some stars (especially among the F-G types) had been measured before. The stars were taken from the second edition of the Catalogue of Nearby Stars (CNS; Gliese 1969) and from its supplement (Gliese \& Jahreiss 1979). The stars discarded from the preliminary third version of the CNS (CNS3; Gliese \& Jahreiss 1991) were kept in the observing runs. All stars were observed with CORAVEL from the Haute-Provence Observatory. Due to the location of the instrument and to its characteristics, only the stars as late as F7 and northern to $-15^{\circ}$ in declination were observed. Some stars with declination below $-15^{\circ}$ were observed, but they were not taken into account in Paper III. The programme was split according to the spectral types of the stars: the search for SBs amongst 288 F-G stars ended in December 1989, but the detection of SBs amongst the 
Table 1. Sample records of the RV measurement catalogues.

\begin{tabular}{|c|c|c|c|c|c|c|}
\hline \multirow[t]{2}{*}{ GJ } & \multicolumn{2}{|c|}{ epoch } & \multirow{2}{*}{$\begin{array}{c}\mathrm{RV} \\
\mathrm{km} \mathrm{s}^{-1}\end{array}$} & \multirow{2}{*}{$\begin{array}{l}\sigma_{\mathrm{RV}} \\
\mathrm{km} \mathrm{s}^{-1}\end{array}$} & \multirow[t]{2}{*}{ comp. } & \multirow[t]{2}{*}{ Remark } \\
\hline & yymmdd & BJD-2400000 & & & & \\
\hline 5 & 780213 & 43553.279 & -5.90 & 0.41 & 1 & \\
\hline 5 & 780825 & 43746.491 & -7.00 & 0.32 & 1 & \\
\hline 5 & 780914 & 43766.509 & -6.08 & 0.35 & 1 & \\
\hline 5 & 830903 & 45581.567 & -5.92 & 0.33 & 1 & \\
\hline 5 & 851219 & 46419.286 & -6.52 & 0.31 & 1 & \\
\hline $\begin{array}{c}. \ddot{3} .1 \mathrm{~A} \\
\end{array}$ & $\begin{array}{c}. . \\
771103\end{array}$ & 43451.441 & 6.94 & $0.3 \ddot{2}$ & $\dot{1}$ & \\
\hline.. &.. &.. & & & . & \\
\hline 1124 & 870330 & 46885.380 & -54.20 & 0.89 & 2 & $\mathrm{R}$ \\
\hline 1069 & 970821 & 50681.6321 & 24.440 & 0.044 & 1 & \\
\hline $55 \ddot{4}$ & $\begin{array}{c}. . \\
980109\end{array}$ & $5082 \ddot{2} .7302$ & -18.863 & 0.014 & $\dot{1}$ & $\mathrm{R}$ \\
\hline
\end{tabular}

Notes. The first records refer to CORAVEL RVs, and the last records refer to the file of the Elodie RV measurements.

K-type stars was intensively performed until July 1993. After this date, the SBs were observed until 2000; at the same time, the RV of a few stars were still measured in order to confirm that it was constant.

\section{Radial-velocity catalogues}

\subsection{CORAVEL individual measurements}

The catalogue of the RV measurements provides 5413 measurements for 269 stars: $261 \mathrm{~K}$-type stars and eight stars from the sample of DM91. These eight G-type stars were already in Paper I or another paper quoted in DM91, but they fulfil two conditions: they received enough additional RV measurements between 1991 and 2000 to significantly improve their spectroscopic orbit, and this new CORAVEL orbit was not published elsewhere. Moreover, the reduction of the CORAVEL observations was slightly improved, and the RV measurements are not exactly the same as in Paper I.

The format of the catalogue is presented in Table 1. Each record consists in the following data:

- The number of the star in the CNS, followed by a letter designating the component, if any.

- The epoch of the observation, given as a date with the year, the month, and the day, and also as barycentric Julian Day (BJD).

- The RV, in $\mathrm{km} \mathrm{s}^{-1}$.

- The uncertainty of the RV.

- The index of component ("1" for the primary, "2" for the secondary).

- A flag "R" indicates the measurement was discarded from the calculation of the orbital elements.

The records are sorted by stars (from the smallest to the largest right ascension), and then by observation epochs.

\subsection{Elodie individual measurements}

The CORAVEL observations were not sufficiently accurate to derive valuable SB orbital elements for two stars of the sample, GJ 1069 and GJ 554. The latter of these two stars is even a constant velocity star when only the CORAVEL RVs are considered. Fortunately, RV measurements were performed thanks to the spectrograph Elodie of the $193 \mathrm{~cm}$ telescope at the HauteProvence Observatory, and they are provided by the Elodie archive $^{1}$. Fifteen Elodie RVs of GJ 1069 and 58 RVs of GJ 554 are presented in a separate file, with a slightly different format due to their accuracy. The uncertainties of the Elodie RVs were estimated as explained in Sect. 4.1. Sample records are presented at the end of Table 1.

\subsection{The mean RV and the detection of SBs}

The RV measurements were used to derive statistical information to decide whether a star is binary or not. These data are provided in Table A.1. The content is the following:

- The identification of the star is the CNS number (GJ), as in the RV catalogue, and another identification, which is HD when it exists, otherwise BD, or HIP, or AG (Astronomische Gesellschaft catalogue). Three stars are designated only by the GJ identification; these stars are all visual secondary components, as indicated by letter "B" following their GJ number: GJ 57.1B, GJ 615.1B, and GJ 764.1B.

- The $B-V$ colour index used to derive the CORAVEL RVs of the star. For the eight stars from the G-type sample, $B-V=$ 0.63 was assumed.

- The mean RV, $\overline{R V}$. When the star is a binary with known orbital elements, the RV of the barycentre is provided, as it is in Table A.2.

$-\epsilon$ is the uncertainty of $\overline{\mathrm{RV}}$.

- $\sigma_{\mathrm{RV}}$ is the standard deviation of the RV measurements.

- $E / I$ is the ratio of external to internal errors.

- $P\left(\chi^{2}\right)$ is the probability to obtain the $\chi^{2}$ of the RVs of the star, assuming that the RV is constant in reality.

- $N_{1}$ is the number of observations of the star.

- $N_{\text {tot }}$ is the number of RV measurements of the primary and of the secondary components.

- $\Delta T$ is the time span of the observation.

- The spectroscopic status is "CST" (ConStanT) when $P\left(\chi^{2}\right)$ is more than $1 \%$. Otherwise, it is SB1, or SB2 when the RV of the secondary component was measured. An " $\mathrm{O}$ " indicates that the orbital elements were derived, as explained in Sect. 4 hereafter. One star, GJ 554, has a constant CORAVEL $\mathrm{RV}$, but an SB orbit derived by adding Elodie RV; this star is flagged "CSTO". The status of two stars (GJ 893.2B and GJ 907.1) is "?" since only one RV measurement was obtained; these stars have both declinations around $-10^{\circ}$, and are too faint to be easily observable. However, they were

1 http://atlas.obs-hp. fr/elodie/ 


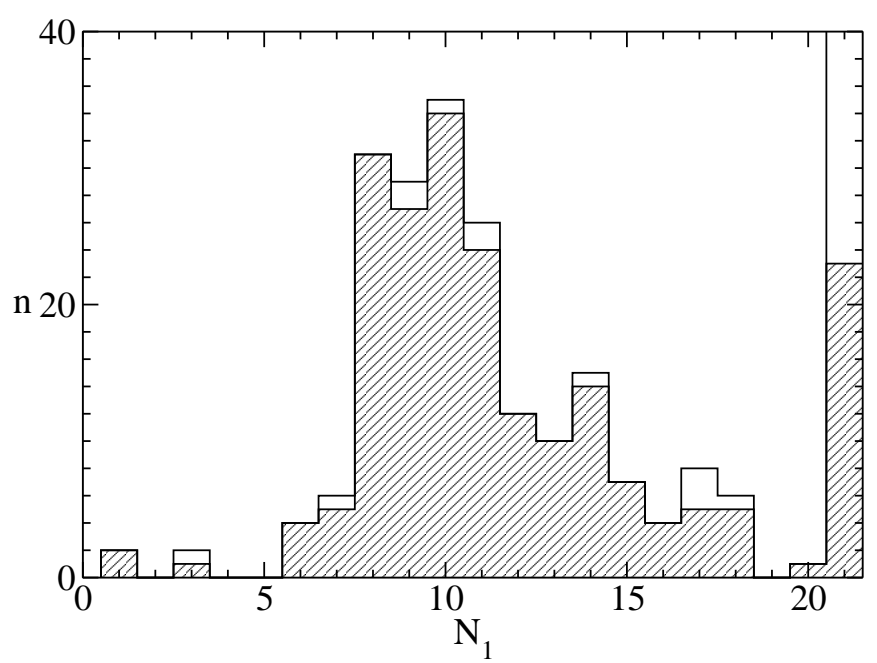

Fig. 1. Histogram of the number of observations. The shaded area refers to the stars that were not considered as variable and the white area to the spectroscopic binaries. The last bin represents all the stars with at least 21 observations; for the spectroscopic binaries, the count in this bin is 72 .

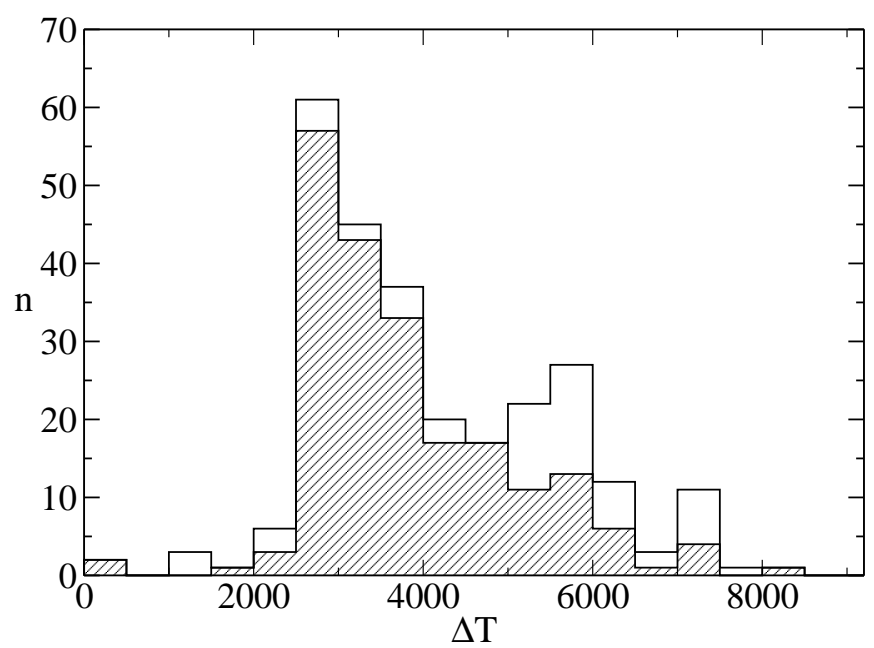

Fig. 2. Histogram of the time span of the observations. The shaded area refers to the stars that were not considered as variable and the white area to the spectroscopic binaries.

only in the so-called "extended sample" of Paper III, and they were not relevant in the statistical investigations.

- A flag indicates that the SB orbital elements of the star are in Table A.2, "*” when they are derived for the first time, and

"+" otherwise. The velocity curves of the flagged stars are in Figs. 3-5.

The efficiency of the detection of the SBs depends on the time spans of the RV survey and on the numbers of RV measurements per star. The histograms of $N_{1}$ and of $\Delta T$ are presented in Figs. 1 and 2, respectively. The stars with variable RV are counted apart from the others, since they received more observations when their variability was detected.

It appears from Fig. 1 that a few stars received much less observations than the others. In addition to the two stars with only one observation already mentioned above, two stars have three observations, although one of them have a variable RV. This star is GJ 142, which was not taken into account in the binarity statistics because its declination is close to $-20^{\circ}$. The other star is GJ 764.1B; it is difficult to observe since it is $5 \operatorname{arcsec}$ away from its brighter companion GJ 764.1A, and it is only in the "extended" sample.

Half of the 209 constant RV stars received 11 observations or less. For the 269 stars in Table A.1, the median number of observations is 12 .

The distribution of the time span, Fig. 2, also indicates that a few stars seem to have been less well observed than others. In addition to the two stars with one measurement and $\Delta T=0,3$ stars were observed during less than 1500 days, although their RVs were variable. In fact, these stars are GJ 1124, GJ 343.1, and GJ 870, three short-period binaries, and their observations were completed in a few years; they received enough RV measurements to derive their orbital elements, which are listed in Table A.2. The median time span is 3689 days for all the 270 stars, and 3410 days for the 209 constant RV stars.

\section{Orbital elements of the spectroscopic binaries}

\subsection{Taking into account the Elodie RV measurements of GJ 1069 and GJ 554}

The accuracy of the CORAVEL RVs precludes the derivation of relevant orbital elements for GJ 1069 and GJ 554, and it was necessary to take into account RVs provided by the Elodie archive. For that purpose, the uncertainty of the Elodie RVs must be estimated in order to assign them a reliable weight with respect to the CORAVEL RVs. For each star, the same weight was assigned to all the Elodie RV measurements and the SB orbital elements were derived from Elodie alone. The residuals of the RVs were calculated and the uncertainty of the RVs was then chosen so that the $F_{2}$ estimator of the goodness-of-fit is zero. According to Stuart \& Ord (1994), $F_{2}$ is derived from theRV formula

$$
F_{2}=\left(\frac{9 v}{2}\right)^{1 / 2}\left[\left(\frac{\chi^{2}}{v}\right)^{1 / 3}+\frac{2}{9 v}-1\right],
$$

where $v$ is the number of degrees of freedom and $\chi^{2}$ is the weighted sum of the squares of the differences between the predicted and the observed RVs, normalised with respect to their uncertainties. It was thus found that the uncertainty is $44 \mathrm{~m} \mathrm{~s}^{-1}$ for GJ 1069 and $14 \mathrm{~m} \mathrm{~s}^{-1}$ for GJ 554. The final elements were then derived taking into account simultaneously the RVs from Elodie and those of CORAVEL. A systematic offset between the two sets of measurements was derived with the SB solution. It is worth noticing that, although the CORAVEL RVs have weights much smaller than those of Elodie, they slightly improve the accuracy of the solution terms.

\subsection{Presentation of the orbital elements}

We used the RV measurements to derive the SB orbital elements for all stars sufficiently observed. The number of these stars is 45; they are flagged "O" in Table A.1. An SB orbit based on our CORAVEL RV measurements has already been published for three of them: GJ 1064B, GJ 692.1, and GJ 765.2; the orbits of the last two stars are even $\mathrm{SB}+\mathrm{VB}$ orbits, since interferometric observations were also taken into account; the references of these three orbits are given in the footnotes of Table A.1. The SB orbital elements of the remaining 42 stars are listed in Table A.2. Since two stars are triple spectroscopic systems, this table contains 44 orbits. 

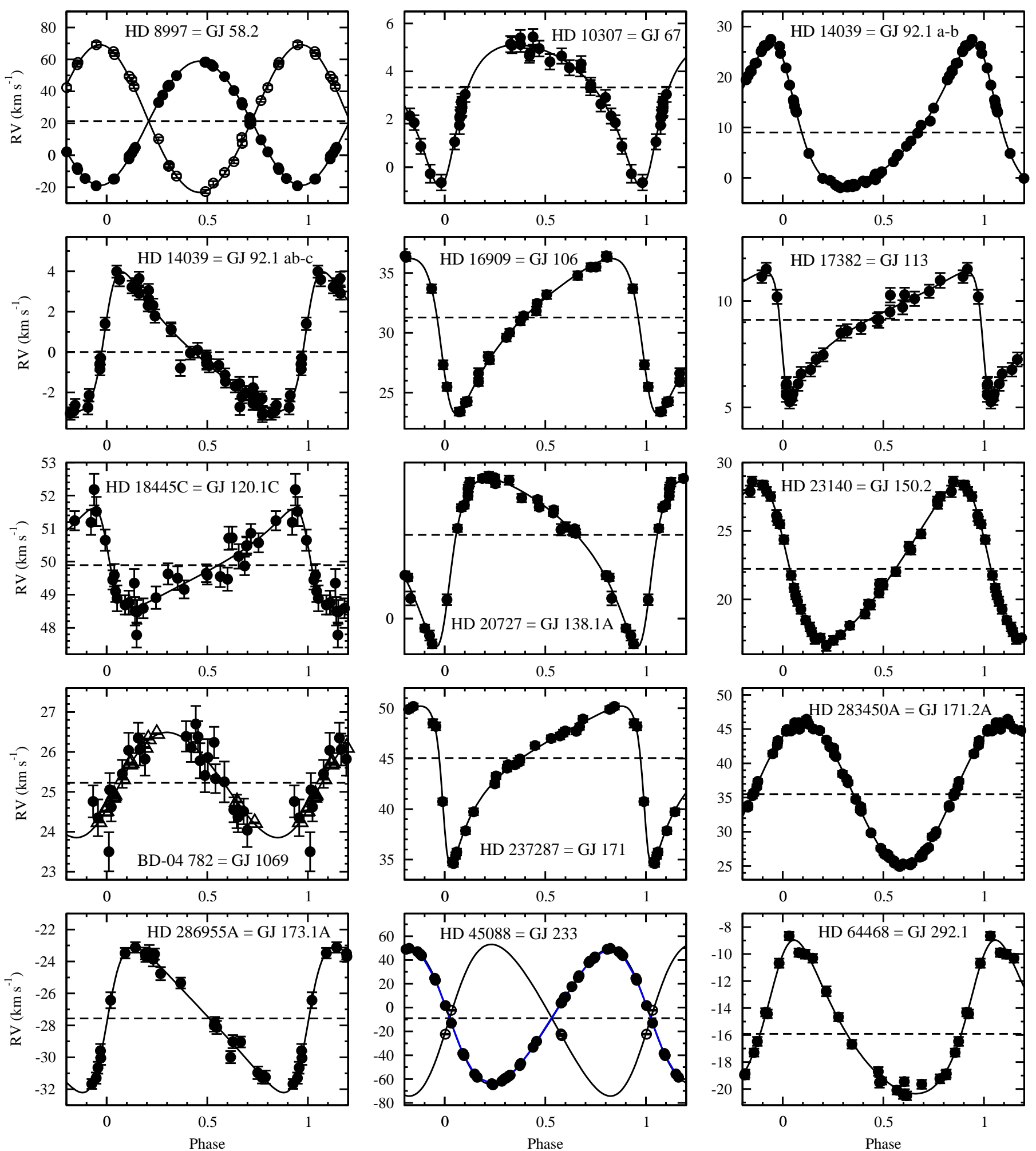

Fig. 3. Spectroscopic orbits of the first $15 \mathrm{SBs}$ in Table A.2; the circles refer to the non-rejected CORAVEL RV measurements and, for GJ 1069, the open triangles refer to the measurements obtained with Elodie; the Elodie RVs are shifted to the zero point of the CORAVEL measurements.

The footnotes of Table A.2 indicate that 23 of these orbits were previously published on the basis of a part of our measurements or from RVs measured with a different instrument than CORAVEL. The 21 other orbits refer to new SBs.

The orbits of eight G-type stars mentioned in DM91 are included in Table A.2. DM91 provided a preliminary orbit for six of these stars, but the orbital elements are significantly improved there, thanks to additional RV measurements. The $44 \mathrm{SB}$ orbits in Table A.2 are presented in Figs. 3-5.

\section{Conclusion}

We have drawn up a catalogue of $5413 \mathrm{RV}$ measurements obtained with CORAVEL for 269 stars, 261 K-type dwarfs, and 

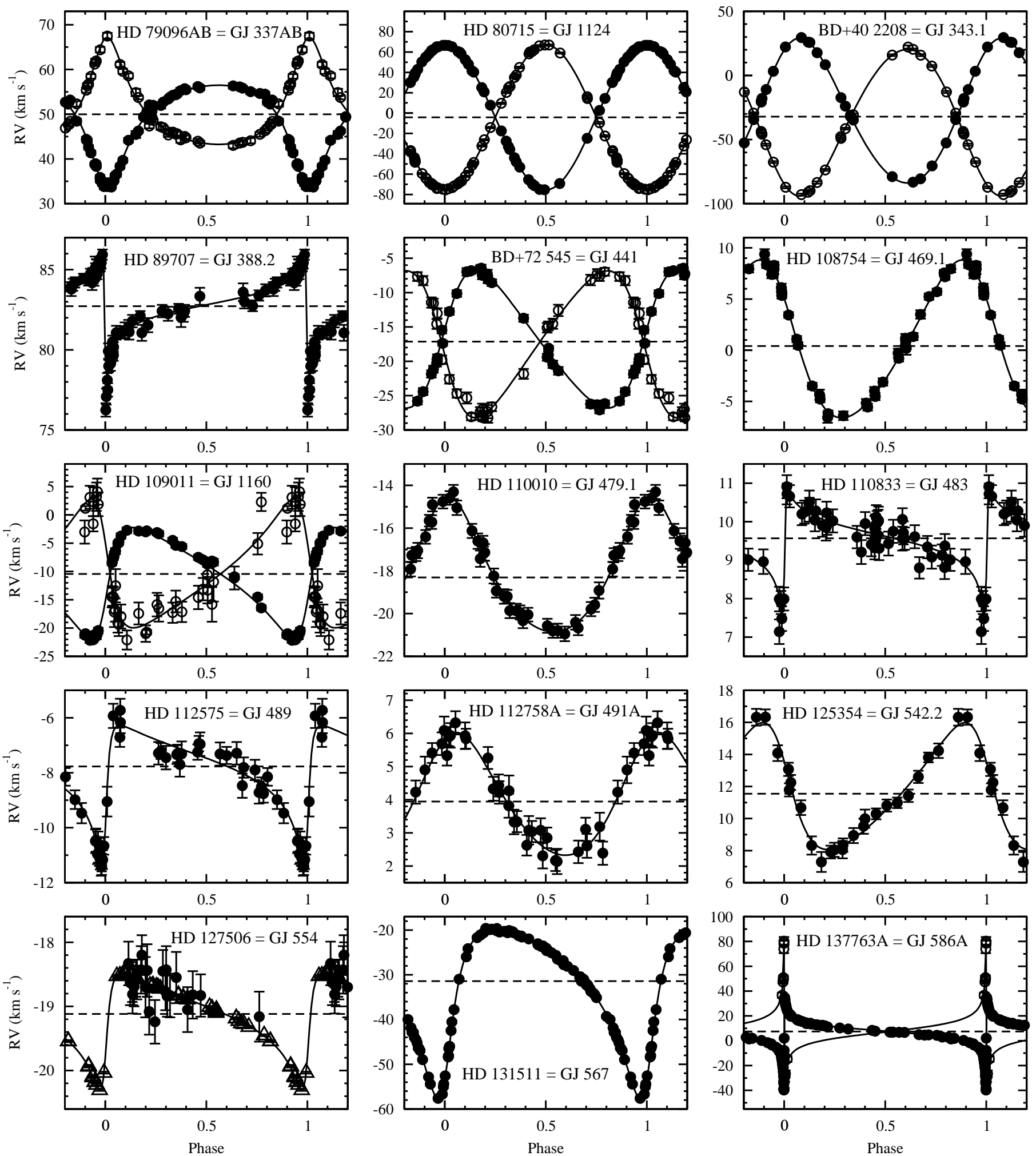

Fig. 4. Spectroscopic orbits of the second set of $15 \mathrm{SBs}$ in Table A.2; the circles refer to the non-rejected CORAVEL RV measurements and, for GJ 554, the open triangles refer to the measurements obtained with Elodie; the Elodie RVs are shifted to the zero point of the CORAVEL measurements.

eight G-type dwarfs of the solar neighbourhood. These measurements were used to detect the SBs on which were based the statistical investigations of Paper III. We calculated the elements of 44 SB orbits, corresponding to 42 stellar systems. Twenty-one orbits, corresponding to 20 stellar systems, are the first orbits ever published for these stars.

All these data will be available through the VizieR service of the Centre de Donnée astronomique de Strasbourg (CDS). The 

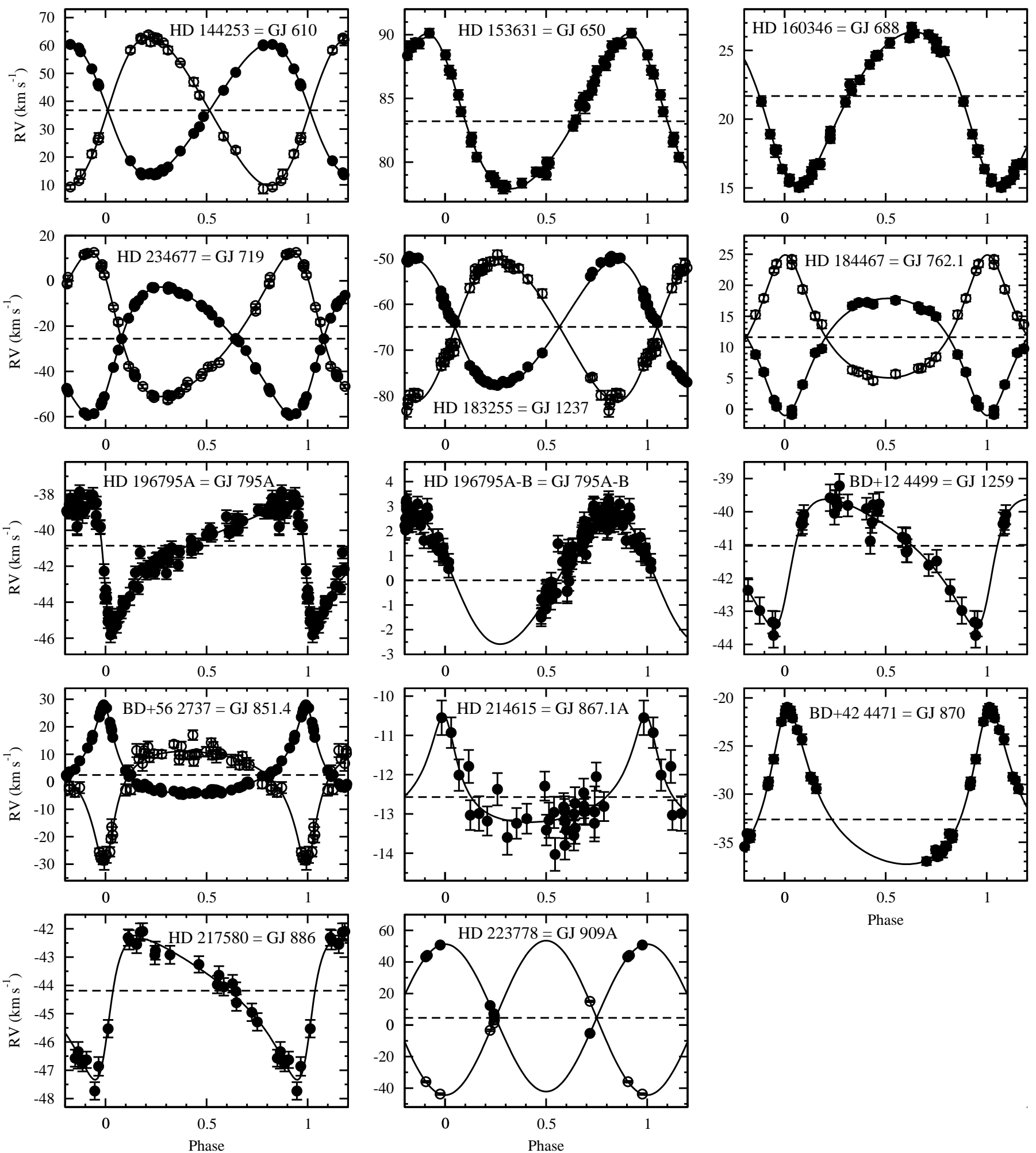

Fig. 5. Spectroscopic orbits of the 14 last SBs in Table A.2; the circles refer to the non-rejected CORAVEL RV measurements.

SB orbits and the corresponding RV measurements will also be included in the on-line SB9 catalogue ${ }^{2}$.

Acknowledgements. It is a pleasure to thank Salim Hillali for his contribution to the derivation of the orbits. The referee, Roger Griffin, indicated some relevant references. We have benefited during the entire period of these observations from the support of the Swiss National Foundation and Geneva University. We are

\footnotetext{
2 http://sb9.astro.ulb.ac. be/, Pourbaix et al. 2004
}

particularly grateful to our technicians Bernard Tartarat, Emile Ischi, and Charles Maire for their dedication to that experiment for more than 20 years. We made use of Simbad, the database of the CDS and of the SB9 catalogue.

\section{References}

Al-Wardat, M. A., Balega, Y. Y., Leushin, V. V., et al. 2014, Astrophys. Bull., 69, 198

Balega, Y. Y., Beuzit, J.-L., Delfosse, X., et al. 2007, A\&A, 464, 635 
J.-L. Halbwachs et al.: Multiplicity among solar-type stars. IV.

Baranne, A., Mayor, M., \& Poncet, J.-L. 1979, Vistas Astron., 23, 279

Batten, A. H., \& Fletcher, J. M. 1991, PASP, 103, 546

Batten, A. H., \& van Dessel, E. L. 1976, Publications of the Dominion Astrophysical Observatory Victoria, 14, 345

Batten, A. H., Fletcher, J. M., \& Campbell, B. 1984, PASP, 96, 903

Beavers, W. I., \& Salzer, J. J. 1983, PASP, 95, 79

Berman, L. 1932, Lick Observatory Bulletin, 16, 24

Bopp, B. W., \& Evans, D. S. 1973, MNRAS, 164, 343

Christie, W. H. 1934, ApJ, 80, 181

Duquennoy, A. 1987, A\&A, 178, 114

Duquennoy, A., \& Mayor, M. 1988, A\&A, 195, 129

Duquennoy, A., \& Mayor, M. 1991, A\&A, 248, 485

Duquennoy, A., Mayor, M., \& Halbwachs, J.-L. 1991, A\&AS, 88, 281

Duquennoy, A., Mayor, M., Andersen, J., Carquillat, J.-M., \& North, P. 1992, A\&A, 254, L13

Duquennoy, A., Tokovinin, A. A., Leinert, C., et al. 1996, A\&A, 314, 846

Eggenberger, A., Halbwachs, J.-L., Udry, S., \& Mayor, M. 2004, Rev. Mex. Astron. Astrofis. Conf. Ser., 21, 28

Gaia Collaboration (Prusti, T., et al.) 2016, A\&A, 595, A1

Gliese, W. 1969, Catalogue of Nearby Stars, Veröffentlichungen des Astronomischen Rechen-Instituts Heidelberg, 22

Gliese, W., \& Jahreiss, H. 1979, A\&AS, 38, 423

Gliese, W., \& Jahreiss, H. 1991, in Preliminary version of the third edition of the Catalogue of Nearby Stars (Heidelberg: Astron. Rechen Inst.)

Griffin, R. F. 1987, The Observatory, 107, 194

Griffin, R. F. 1991, The Observatory, 111, 37

Griffin, R. F., \& Emerson, B. 1975, The Observatory, 95, 23

Griffin, R. F., \& Griffin, R. E. M. 1982, The Observatory, 102, 217

Griffin, R. F., \& Griffin, R. E. M. 1983, PASP, 95, 889
Griffin, R. F., Griffin, R. E. M., Gunn, J. E., \& Zimmerman, B. A. 1985, AJ, 90, 609

Halbwachs, J.-L., Mayor, M., Udry, S., \& Arenou, F. 2003, A\&A, 397, 159

Heintz, W. D. 1988, JRASC, 82, 140

Jasniewicz, G., \& Mayor, M. 1988, A\&A, 203, 329

Kamper, K. W., \& Lyons, R. W. 1981, JRASC, 75, 56

Katoh, N., Itoh, Y., Toyota, E., \& Sato, B. 2013, AJ, 145, 41

Katoh, N., Itoh, Y., Toyota, E., \& Sato, B. 2016, AJ, 151, 87

Kiefer, F., Halbwachs, J.-L., Lebreton, Y., et al. 2018, MNRAS, 474, 731

Latham, D. W., Stefanik, R. P., Torres, G., et al. 2002, AJ, 124, 1144

Mason, B. D., McAlister, H. A., \& Hartkopf, W. I. 1996, AJ, 112, 276

McClure, R. D. 1983, PASP, 95, 201

Nidever, D. L., Marcy, G. W., Butler, R. P., Fischer, D. A., \& Vogt, S. S. 2002, ApJS, 141, 503

Pourbaix, D. 2000, A\&AS, 145, 215

Pourbaix, D., Tokovinin, A. A., Batten, A. H., et al. 2004, A\&A, 424, 727

Raghavan, D., McAlister, H. A., Henry, T. J., et al. 2010, ApJS, 190, 1

Sahlmann, J., Ségransan, D., Queloz, D., et al. 2011, A\&A, 525, A95

Scarfe, C. D. 1988, JRASC, 82, 274

Stuart, A., \& Ord, K. 1994, in Kendall's Advanced Theory of Statistics (London: Edward Arnold), 1

Tokovinin, A. A. 1990, Sov. Astron. Lett., 16, 440

Tokovinin, A. A. 1991, A\&AS, 91, 497

Tokovinin, A. A., \& Latham, D. W. 2017, ApJ, 838, A54

Tokovinin, A. A., Duquennoy, A., Halbwachs, J.-L., \& Mayor, M. 1994, A\&A, 282,831

Tokovinin, A. A., Mason, B. D., Hartkopf, W. I., Mendez, R. A., \& Horch, E. P. 2015, AJ, 150, 50

Vogt, S. S., \& Fekel, F. J. 1979, ApJ, 234, 958 


\section{Appendix A: Tables of mean RVs and of orbital elements}

Table A.1. Average RV and the variability status.

\begin{tabular}{|c|c|c|c|c|c|c|c|c|c|c|c|c|c|}
\hline \multicolumn{3}{|c|}{ Identifications } & \multirow{2}{*}{$B-V$} & \multirow{2}{*}{$\begin{array}{c}\overline{\mathrm{RV}} \\
\mathrm{km} \mathrm{s}^{-1}\end{array}$} & \multirow{2}{*}{$\begin{array}{r}\epsilon \\
\mathrm{km} \mathrm{s}^{-1}\end{array}$} & \multirow{2}{*}{$\begin{array}{c}\sigma_{\mathrm{RV}} \\
\mathrm{km} \mathrm{s}^{-1}\end{array}$} & \multirow[t]{2}{*}{$E / I$} & \multirow[t]{2}{*}{$P\left(\chi^{2}\right)$} & \multirow[t]{2}{*}{$N_{1}$} & \multirow[t]{2}{*}{$N_{\text {tot }}$} & \multirow{2}{*}{$\begin{array}{r}\Delta T \\
\text { days }\end{array}$} & \multirow{2}{*}{$\begin{array}{l}\text { spect. } \\
\text { status }\end{array}$} & \multirow{2}{*}{$\begin{array}{c}\text { Table } \\
\text { A. } 2 \\
\end{array}$} \\
\hline GJ & $\mathrm{HD} / \mathrm{H}$ & /HIP/AG & & & & & & & & & & & \\
\hline 5 & HD & 166 & 0.75 & -6.57 & 0.07 & 0.33 & 1.13 & 0.195 & 21 & 21 & 5410 & CST & \\
\hline 27 & HD & 3651 & 0.85 & -32.99 & 0.06 & 0.32 & 1.11 & 0.198 & 25 & 25 & 4043 & CST & \\
\hline 28 & HD & 3765 & 0.93 & -63.28 & 0.02 & 0.25 & 0.82 & 1.000 & 183 & 183 & 8037 & CST & \\
\hline 30 & $\mathrm{BD}$ & +3399 & 1.13 & -36.29 & 0.10 & 0.31 & 0.94 & 0.540 & 10 & 10 & 2884 & CST & \\
\hline 31.4 & HD & 4256 & 0.99 & 9.40 & 0.09 & 0.24 & 0.77 & 0.838 & 12 & 12 & 3262 & CST & \\
\hline 33 & HD & 4628 & 0.88 & -10.33 & 0.08 & 0.34 & 1.11 & 0.242 & 17 & 17 & 5132 & CST & \\
\hline 39 & HD & 4913 & 1.21 & 6.56 & 0.10 & 0.32 & 0.90 & 0.666 & 14 & 14 & 3266 & CST & \\
\hline 44 & $\mathrm{BD}$ & -02129 & 0.83 & -48.00 & 0.11 & 0.26 & 0.72 & 0.863 & 10 & 10 & 3261 & CST & \\
\hline 50 & $\mathrm{BD}$ & -10216 & 1.25 & -1.16 & 0.09 & 0.52 & 1.19 & 0.075 & 33 & 33 & 5588 & CST & \\
\hline 52 & $\mathrm{BD}$ & +63137 & 1.30 & 2.73 & 0.13 & 0.41 & 1.06 & 0.350 & 10 & 10 & 2994 & CST & \\
\hline $53.1 \mathrm{~A}$ & HD & 6660 & 1.12 & 6.58 & 0.08 & 0.28 & 0.87 & 0.719 & 15 & 15 & 4838 & CST & \\
\hline 53.2 & $\mathrm{BD}$ & +16120 & 1.27 & -57.42 & 0.14 & 0.39 & 0.93 & 0.579 & 9 & 9 & 2623 & CST & \\
\hline 55.2 & HIP & 5957 & 1.36 & -23.66 & 0.13 & 0.28 & 0.70 & 0.868 & 9 & 9 & 2629 & CST & \\
\hline 56 & HD & 7808 & 1.00 & -7.31 & 0.13 & 0.30 & 0.71 & 0.896 & 11 & 11 & 2968 & CST & \\
\hline $56.3 \mathrm{~A}$ & HD & 7895 & 0.82 & 16.37 & 0.09 & 0.24 & 0.76 & 0.870 & 13 & 13 & 3603 & CST & \\
\hline 56.4 & $\mathrm{BD}$ & +7938 & 1.29 & -20.61 & 0.13 & 0.37 & 0.94 & 0.529 & 9 & 9 & 2626 & CST & \\
\hline 56.5 & HD & 7924 & 0.82 & -22.63 & 0.10 & 0.26 & 0.81 & 0.727 & 9 & 9 & 2621 & CST & \\
\hline $57.1 \mathrm{~A}$ & HD & 8389 & 0.91 & 34.55 & 0.08 & 0.25 & 0.81 & 0.811 & 14 & 14 & 2955 & CST & \\
\hline $57.1 \mathrm{~B}$ & & & 1.38 & 34.78 & 0.12 & 0.43 & 0.95 & 0.573 & 13 & 13 & 2955 & CST & \\
\hline 58.2 & HD & 8997 & 0.96 & 21.35 & 0.10 & 27.50 & 60.04 & 0.000 & 31 & 54 & 2662 & SB2O & + \\
\hline 1040 & HIP & 7655 & 1.20 & 32.30 & 0.15 & 0.52 & 1.23 & 0.134 & 12 & 12 & 5229 & CST & \\
\hline 67 & HD & 10307 & 0.63 & 3.33 & 0.05 & 1.59 & 4.90 & 0.000 & 32 & 32 & 7416 & SB1O & + \\
\hline 68 & HD & 10476 & 0.84 & -33.67 & 0.08 & 0.24 & 0.80 & 0.844 & 15 & 15 & 5846 & CST & \\
\hline 69 & HD & 10436 & 1.22 & -50.94 & 0.10 & 0.31 & 0.88 & 0.680 & 13 & 13 & 2958 & CST & \\
\hline 74 & HD & 10853 & 1.04 & 21.56 & 0.10 & 0.36 & 1.00 & 0.462 & 13 & 13 & 3249 & CST & \\
\hline 75 & HD & 10780 & 0.81 & 2.82 & 0.08 & 0.28 & 0.90 & 0.642 & 14 & 14 & 4711 & CST & \\
\hline 90 & HD & 13579 & 0.92 & -12.58 & 0.10 & 0.17 & 0.58 & 0.950 & 9 & 9 & 2621 & CST & \\
\hline $91.1 \mathrm{~A}$ & HD & 13959 & 1.10 & -0.17 & 0.11 & 0.54 & 1.42 & 0.004 & 23 & 23 & 7428 & SB1? & \\
\hline $91.2 \mathrm{~A}$ & HD & 14001 & 1.02 & 2.89 & 0.12 & 0.24 & 0.65 & 0.922 & 10 & 10 & 5427 & CST & \\
\hline 92.1 & HD & 14039 & 0.92 & 9.02 & 0.05 & 11.14 & 34.47 & 0.000 & 52 & 52 & 5588 & SB1O & $*$ \\
\hline $98 \mathrm{~A}$ & HD & 15285 & 1.39 & 6.57 & 0.14 & 4.71 & 3.95 & 0.000 & 27 & 54 & 7410 & SB2 & \\
\hline $105 \mathrm{~A}$ & HD & 16160 & 0.97 & 25.53 & 0.06 & 0.28 & 0.95 & 0.603 & 24 & 24 & 6837 & CST & \\
\hline 106 & HD & 16909 & 1.07 & 31.28 & 0.06 & 4.41 & 13.32 & 0.000 & 23 & 23 & 3604 & SB1O & + \\
\hline 112 & HD & 17190 & 0.84 & 14.00 & 0.08 & 0.28 & 0.92 & 0.631 & 15 & 15 & 2891 & CST & \\
\hline 112.1 & HD & 17230 & 1.28 & 11.01 & 0.10 & 0.32 & 0.91 & 0.623 & 12 & 12 & 3303 & CST & \\
\hline 113 & HD & 17382 & 0.82 & 9.11 & 0.06 & 2.07 & 6.47 & 0.000 & 26 & 26 & 5592 & SB1O & + \\
\hline 114 & HD & 17660 & 1.27 & -29.02 & 0.12 & 0.28 & 0.81 & 0.731 & 9 & 9 & 2615 & CST & \\
\hline 117 & HD & 17925 & 0.87 & 17.92 & 0.06 & 0.30 & 1.02 & 0.422 & 24 & 24 & 4851 & CST & \\
\hline $118.2 \mathrm{~A}$ & HD & 18143 & 0.93 & 32.06 & 0.11 & 0.17 & 0.54 & 0.959 & 8 & 8 & 2950 & CST & \\
\hline $120.1 \mathrm{C}$ & HD & 18445 & 0.63 & 49.90 & 0.07 & 0.93 & 2.85 & 0.000 & 32 & 32 & 5929 & SB1O & $*$ \\
\hline $138.1 \mathrm{~A}$ & HD & 20727 & 0.63 & 7.51 & 0.08 & 4.07 & 12.17 & 0.000 & 31 & 31 & 3982 & SB1O & + \\
\hline 141 & HD & 21197 & 1.16 & -13.22 & 0.10 & 0.29 & 0.94 & 0.546 & 10 & 10 & 2959 & CST & \\
\hline 142 & HD & 21531 & 1.34 & 34.35 & 0.58 & 1.00 & 3.04 & 0.000 & 3 & 3 & 2039 & SB1 & \\
\hline
\end{tabular}

Notes. A flag in the last column indicates that the orbital elements are presented in Table A.2; it is “*” when the orbital elements are derived for the first time, and "+" otherwise. ${ }^{(1)}$ Our measurements were taken into account in the SB orbit of Tokovinin et al. (1994). (2) The RV is constant when the measurement of 13 April 1987 is discarded. ${ }^{(3)}$ The SB nature of the star was inferred from Elodie observations. ${ }^{(4)}$ The RV is constant when the measurement of 22 May 1983 is discarded. ${ }^{(5)}$ Our RV measurements were used by Duquennoy et al. (1996) to derive a combined spectroscopic and interferometric orbit. ${ }^{(6)}$ Combined spectroscopic and visual orbit by Berman (1932), Batten \& van Dessel (1976), Batten et al. (1984), Heintz (1988), Batten \& Fletcher (1991), and Pourbaix (2000). Griffin \& Griffin (1983) and Griffin (1991) pointed out the risk that the RV measurements are distorted due to contamination by the secondary component. ${ }^{(7)}$ Our RV measurements were used by Balega et al. (2007) to derive a combined spectroscopic and interferometric orbit. 
Table A.1. continued.

\begin{tabular}{|c|c|c|c|c|c|c|c|c|c|c|c|c|c|}
\hline 144 & HD & 22049 & 0.88 & 16.31 & 0.06 & 0.28 & 1.02 & 0.407 & 21 & 21 & 3989 & CST & \\
\hline 150.2 & HD & 23140 & 0.86 & 22.24 & 0.04 & 3.94 & 12.38 & 0.000 & 38 & 38 & 5585 & SB1O & * \\
\hline $153 \mathrm{~A}$ & HD & 23189 & 1.30 & 2.58 & 0.14 & 0.20 & 0.48 & 0.986 & 9 & 9 & 3984 & CST & \\
\hline 1063 & $\mathrm{BD}$ & +11514 & 1.18 & 83.73 & 0.13 & 0.10 & 0.28 & 0.999 & 8 & 8 & 2889 & CST & \\
\hline $1064 \mathrm{~A}$ & HD & 23439 & 0.78 & 50.66 & 0.12 & 0.40 & 1.03 & 0.388 & 11 & 11 & 6113 & CST & \\
\hline $1064 \mathrm{~B}$ & $A G$ & +41397 & 0.90 & 51.19 & 0.06 & 7.08 & 18.94 & 0.000 & 29 & 29 & 3344 & $\mathrm{SB}_{10}{ }^{1}$ & \\
\hline 155.2 & HD & 24238 & 0.83 & 38.95 & 0.12 & 0.23 & 0.70 & 0.842 & 8 & 8 & 2265 & CST & \\
\hline 156.2 & HD & 24451 & 1.15 & 17.69 & 0.10 & 0.20 & 0.62 & 0.945 & 10 & 10 & 3245 & CST & \\
\hline $157 \mathrm{~A}$ & HD & 24916 & 1.12 & 3.64 & 0.11 & 0.29 & 0.85 & 0.687 & 9 & 9 & 3405 & CST & \\
\hline 158 & HD & 25329 & 0.88 & -25.89 & 0.13 & 0.53 & 1.16 & 0.173 & 17 & 17 & 5564 & CST & \\
\hline 161 & HD & 25665 & 0.91 & -13.57 & 0.10 & 0.30 & 0.94 & 0.552 & 10 & 10 & 3245 & CST & \\
\hline 165.1 & HD & 26581 & 1.00 & 23.99 & 0.12 & 0.25 & 0.74 & 0.804 & 8 & 8 & 3136 & CST & \\
\hline 165.2 & HD & 26794 & 0.97 & 56.51 & 0.11 & 0.36 & 1.00 & 0.448 & 10 & 10 & 3410 & CST & \\
\hline 1069 & BD & -04782 & 1.22 & 25.23 & 0.02 & 0.85 & 2.15 & 0.000 & 25 & 25 & 5223 & SB1O & $*$ \\
\hline $166 \mathrm{~A}$ & HD & 26965 & 0.82 & -42.52 & 0.07 & 0.35 & 1.16 & 0.131 & 22 & 22 & 5913 & CST & \\
\hline 168 & BD & +47977 & 1.17 & -78.60 & 0.13 & 0.37 & 0.97 & 0.480 & 8 & 8 & 3248 & CST & \\
\hline 171 & HD & 237287 & 0.89 & 45.06 & 0.09 & 4.86 & 15.09 & 0.000 & 26 & 26 & 5517 & SB1O & + \\
\hline $171.2 \mathrm{~A}$ & HD & 283750 & 1.12 & 35.51 & 0.04 & 7.70 & 22.48 & 0.000 & 54 & 54 & 2492 & SB1O & + \\
\hline $173.1 \mathrm{~A}$ & HD & 286955 & 1.02 & -27.57 & 0.08 & 3.23 & 8.65 & 0.000 & 24 & 24 & 3306 & SB1O & * \\
\hline 174 & HD & 29697 & 1.19 & 1.01 & 0.06 & 0.32 & 1.00 & 0.482 & 30 & 30 & 5840 & CST & \\
\hline 176.2 & HD & 29883 & 0.92 & 17.67 & 0.10 & 0.24 & 0.74 & 0.845 & 10 & 10 & 3245 & CST & \\
\hline 2035 & HD & 30973 & 1.01 & 26.24 & 0.13 & 0.29 & 0.80 & 0.721 & 8 & 8 & 2891 & CST & \\
\hline 183 & HD & 32147 & 1.06 & 21.45 & 0.07 & 0.24 & 0.82 & 0.839 & 18 & 18 & 4164 & CST & \\
\hline 200 & HD & 34673 & 1.04 & 87.84 & 0.09 & 0.22 & 0.71 & 0.886 & 11 & 11 & 2628 & CST & \\
\hline 1076 & BD & +54886 & 1.30 & 53.71 & 0.14 & 0.57 & 1.55 & 0.002 & 17 & 17 & 5409 & SB1? & \\
\hline 204 & HD & 36003 & 1.10 & -55.72 & 0.11 & 0.36 & 1.16 & 0.211 & 10 & 10 & 2628 & CST & \\
\hline 211 & HD & 37394 & 0.84 & 1.35 & 0.09 & 0.35 & 1.15 & 0.186 & 14 & 14 & 4802 & CST & \\
\hline 217 & HD & 38230 & 0.83 & -29.17 & 0.09 & 0.27 & 0.84 & 0.768 & 14 & 14 & 3140 & CST & \\
\hline 221 & $\mathrm{BD}$ & -061339 & 1.32 & 22.87 & 0.18 & 0.50 & 1.10 & 0.302 & 8 & 8 & 3425 & CST & \\
\hline 223 & HD & 39715 & 1.01 & -33.80 & 0.13 & 0.33 & 0.92 & 0.560 & 8 & 8 & 3399 & CST & \\
\hline 226.2 & HIP & 29067 & 1.25 & -1.90 & 0.13 & 0.20 & 0.52 & 0.977 & 9 & 9 & 3256 & CST & \\
\hline 227 & HD & 41593 & 0.81 & -9.75 & 0.09 & 0.24 & 0.78 & 0.816 & 11 & 11 & 4815 & CST & \\
\hline 233 & HD & 45088 & 0.94 & -8.92 & 0.08 & 42.25 & 139.71 & 0.000 & 41 & 46 & 5603 & SB2O & + \\
\hline 241 & HD & 47752 & 1.02 & -44.29 & 0.10 & 0.12 & 0.36 & 0.999 & 11 & 11 & 3072 & CST & \\
\hline 249 & HD & 49601 & 1.24 & 19.44 & 0.14 & 0.46 & 1.27 & 0.107 & 11 & 11 & 2943 & CST & \\
\hline $250 \mathrm{~A}$ & HD & 50281 & 1.05 & -7.20 & & 0.39 & 1.29 & 0.076 & 12 & 12 & 3238 & CST & \\
\hline 254 & HD & 266611 & 1.36 & -14.95 & 0.15 & 0.40 & 0.90 & 0.603 & 9 & 9 & 4410 & CST & \\
\hline 256 & HD & 51849 & 1.13 & -5.84 & 0.39 & 1.47 & 3.45 & 0.000 & 14 & 14 & 5416 & SB1 & \\
\hline 257.1 & HD & 51866 & 0.99 & -21.51 & 0.11 & 0.28 & 0.86 & 0.664 & 9 & 9 & 3071 & CST & \\
\hline 1094 & HD & 52919 & 1.08 & -30.81 & 0.12 & 0.30 & 0.85 & 0.688 & 9 & 9 & 2561 & CST & \\
\hline 267 & HD & 54359 & 0.96 & 26.44 & 0.12 & 0.33 & 0.93 & 0.553 & 9 & 9 & 4611 & CST & \\
\hline 273.1 & $\mathrm{BD}$ & +321561 & 0.95 & -3.98 & 0.09 & 0.24 & 0.82 & 0.776 & 12 & 12 & 2601 & CST & \\
\hline 276 & HD & 59582 & 1.10 & 66.03 & 0.12 & 0.26 & 0.71 & 0.860 & 9 & 9 & 2615 & CST & \\
\hline $282 \mathrm{~A}$ & HD & 61606 & 0.96 & -18.21 & 0.09 & 0.31 & 1.02 & 0.418 & 11 & 11 & 4760 & CST & \\
\hline $282 \mathrm{~B}$ & $\mathrm{BD}$ & -032002 & 1.3 & -19.02 & 0. & 0.43 & 1.10 & & 10 & 10 & 4760 & CST & \\
\hline 292.1 & HD & 64468 & 0.95 & -15.91 & 0.10 & 3.97 & 12.55 & 0.000 & 24 & 24 & 6124 & SB1O & $*$ \\
\hline 293.1A & HD & 65277 & 1.04 & -4.34 & 0.13 & 0.37 & 1.10 & 0.294 & 8 & 8 & 2958 & CST & \\
\hline 295.1 & BD & +141802 & 1.28 & 20.35 & 0.19 & 0.55 & 1.33 & 0.103 & 8 & 8 & 3984 & CST & \\
\hline 301.1 & $\mathrm{BD}$ & +311781 & 1.14 & 13.47 & 0.10 & 0.31 & 0.97 & & 10 & 10 & 2617 & CST & \\
\hline 313 & HD & 73583 & 1.12 & 20.22 & 0.13 & 0.22 & 0.61 & 0.925 & 8 & 8 & 3277 & CST & \\
\hline 315 & HD & 73667 & 0.82 & -12.03 & 0.11 & 0.25 & 0.75 & 0.808 & 9 & 9 & 3591 & CST & \\
\hline 1113 & HD & 73554 & 1.08 & 54.61 & 0.13 & 0.19 & 0.53 & 0.962 & 8 & 8 & 3303 & CST & \\
\hline 321 & HD & 74377 & 0.94 & -23.63 & 0.15 & 0.41 & 1.22 & 0.182 & 7 & 7 & 3593 & CST & \\
\hline $325 \mathrm{~A}$ & HD & 75632 & 1.39 & 43.52 & 0.97 & 2.92 & 3.27 & 0.000 & 9 & 18 & 5516 & SB2 & \\
\hline 330.1 & BD & +211949 & 1.11 & -50.36 & 0.14 & 0.14 & 0.35 & 0.997 & 8 & 8 & 3936 & CST & \\
\hline 334.1 & $\mathrm{BD}$ & +73447 & 1.26 & -27.09 & 0.16 & 0.46 & 1.03 & 0.409 & 8 & 8 & 5056 & CST & \\
\hline $337 \mathrm{~A}$ & HD & 79096 & 0.73 & 49.99 & 0.07 & 8.50 & 11.27 & 0.000 & 56 & 101 & 5391 & SB2O & + \\
\hline $338.1 \mathrm{~A}$ & $\mathrm{BD}$ & +77361 & 1.38 & -11.34 & 0.19 & 0.56 & 1.25 & 0.149 & 9 & 9 & 4050 & CST & \\
\hline
\end{tabular}


Table A.1. continued.

\begin{tabular}{|c|c|c|c|c|c|c|c|c|c|c|c|c|c|}
\hline 339 & HD & 79555 & 1.02 & 6.74 & 0.22 & 0.70 & 2.18 & 0.000 & 10 & 10 & 3991 & SB1 & \\
\hline $340 \mathrm{~A}$ & HD & 79969 & 1.02 & -20.52 & 0.06 & 0.23 & 0.72 & 0.983 & 27 & 27 & 5796 & CST & \\
\hline 340.2 & HD & 80367 & 0.87 & 50.95 & 0.11 & 0.31 & 0.93 & 0.549 & 9 & 9 & 4091 & CST & \\
\hline 340.3 & HD & 80632 & 1.17 & 36.55 & 0.13 & 0.30 & 0.77 & 0.800 & 9 & 9 & 3703 & CST & \\
\hline 1124 & HD & 80715 & 0.99 & -4.23 & 0.08 & 48.85 & 90.03 & 0.000 & 48 & 100 & 1462 & SB2O & $*$ \\
\hline 341.1 & $\mathrm{BD}$ & +81297 & 1.23 & -18.02 & 0.17 & 0.44 & 1.23 & 0.183 & 7 & 7 & 3598 & CST & \\
\hline 342 & HD & 80768 & 1.19 & -6.32 & 0.10 & 0.27 & 0.69 & 0.938 & 14 & 14 & 3613 & CST & \\
\hline 343.1 & $\mathrm{BD}$ & +402208 & 1.32 & -32.13 & 0.13 & 36.78 & 53.52 & 0.000 & 21 & 44 & 1129 & SB2O & $*$ \\
\hline 349 & HD & 82106 & 1.00 & 29.97 & 0.10 & 0.19 & 0.60 & 0.955 & 10 & 10 & 3694 & CST & \\
\hline 355 & HD & 82558 & 0.91 & 7.58 & 0.27 & 0.81 & 1.17 & 0.211 & 9 & 9 & 2140 & CST & \\
\hline 365 & HD & 84035 & 1.15 & -12.30 & 0.11 & 0.32 & 1.01 & 0.421 & 8 & 8 & 3598 & CST & \\
\hline 378.1 & HD & 86856 & 1.07 & 30.35 & 0.11 & 0.32 & 0.94 & 0.551 & 9 & 9 & 5073 & CST & \\
\hline 379 A & $\mathrm{BD}$ & +75403 & 1.40 & -55.35 & 0.20 & 0.50 & 1.12 & 0.306 & 6 & 6 & 3563 & CST & \\
\hline 380 & HD & 88230 & 1.36 & -26.21 & 0.09 & 0.22 & 0.70 & 0.898 & 11 & 11 & 3568 & CST & \\
\hline 388.2 & HD & 89707 & 0.63 & 82.70 & 0.09 & 2.34 & 6.26 & 0.000 & 64 & 64 & 6144 & SB1O & + \\
\hline 389.1 & $\mathrm{BD}$ & -093063 & 1.23 & -3.97 & 0.30 & 0.90 & 2.20 & 0.000 & 9 & 9 & 5145 & $\mathrm{SB} 1^{2}$ & \\
\hline 394 & HD & 237903 & 1.36 & 8.84 & 0.15 & 0.23 & 0.63 & 0.856 & 6 & 6 & 3663 & CST & \\
\hline 396 & HD & 90343 & 0.82 & 9.80 & 0.10 & 0.30 & 0.95 & 0.520 & 9 & 9 & 3691 & CST & \\
\hline 397 & $\mathrm{BD}$ & +461635 & 1.33 & 20.62 & 0.10 & 0.35 & 1.02 & 0.434 & 13 & 13 & 3979 & CST & \\
\hline 402.1 & $\mathrm{BD}$ & +002709 & 0.90 & -48.33 & 0.13 & 0.30 & 0.72 & 0.873 & 10 & 10 & 4769 & CST & \\
\hline 1139 & $\mathrm{BD}$ & +76404 & 1.10 & -25.82 & 0.15 & 0.43 & 1.02 & 0.402 & 8 & 8 & 3037 & CST & \\
\hline $414 \mathrm{~A}$ & HD & 97101 & 1.35 & -16.63 & 0.11 & 0.27 & 0.75 & 0.846 & 11 & 11 & 3984 & CST & \\
\hline 418 & HD & 97503 & 1.18 & 16.41 & 0.11 & 0.31 & 0.89 & 0.626 & 10 & 10 & 3988 & CST & \\
\hline $420 \mathrm{~A}$ & HD & 97584 & 1.04 & 9.12 & 0.12 & 0.31 & 0.97 & 0.467 & 7 & 7 & 3602 & CST & \\
\hline $426 \mathrm{~A}$ & HD & 98736 & 0.89 & -3.37 & 0.11 & 0.23 & 0.74 & 0.798 & 8 & 8 & 3960 & CST & \\
\hline 429 & HD & 99491 & 0.80 & 4.14 & 0.09 & 0.26 & 0.85 & 0.727 & 13 & 13 & 4754 & CST & \\
\hline $429 \mathrm{~B}$ & HD & 99492 & 1.00 & 3.59 & 0.13 & 0.29 & 0.96 & 0.469 & 6 & 6 & 3607 & CST & \\
\hline 435.1 & $\mathrm{BD}$ & +052529 & 1.24 & 19.48 & 0.45 & 2.48 & 3.43 & 0.000 & 31 & 57 & 5759 & SB2 & \\
\hline 439 & $\mathrm{BD}$ & +312290 & 1.13 & 29.88 & 0.12 & 0.17 & 0.50 & 0.973 & 8 & 8 & 3229 & CST & \\
\hline 441 & BD & +72545 & 1.17 & -17.13 & 0.10 & 7.08 & 8.75 & 0.000 & 29 & 56 & 5453 & SB2O & $*$ \\
\hline $444 \mathrm{~A}$ & HD & 102392 & 1.12 & 18.99 & 0.11 & 0.28 & 0.77 & 0.814 & 10 & 10 & 3689 & CST & \\
\hline 454 & HD & 104304 & 0.76 & 0.28 & 0.08 & 0.28 & 0.96 & 0.523 & 12 & 12 & 4774 & CST & \\
\hline 469.1 & HD & 108754 & 0.63 & 0.40 & 0.07 & 5.11 & 14.71 & 0.000 & 39 & 39 & 3692 & SB1O & + \\
\hline 1160 & HD & 109011 & 0.93 & -10.45 & 0.15 & 6.99 & 11.73 & 0.000 & 35 & 70 & 5475 & SB2O & * \\
\hline 479.1 & HD & 110010 & 0.63 & -18.31 & 0.05 & 2.12 & 6.30 & 0.000 & 36 & 36 & 6141 & SB1O & + \\
\hline 481 & HD & 110315 & 1.12 & 24.90 & 0.10 & 0.24 & 0.71 & 0.873 & 10 & 10 & 3292 & CST & \\
\hline 483 & HD & 110833 & 0.94 & 9.52 & 0.15 & 0.79 & 2.63 & 0.000 & 48 & 48 & 6129 & SB1O & $*$ \\
\hline 488.2 & $\mathrm{BD}$ & -053596 & 1.34 & -12.84 & 0.14 & 0.49 & 1.15 & 0.224 & 12 & 12 & 3297 & CST & \\
\hline 489 & HD & 112575 & 1.12 & -7.77 & 0.06 & 1.80 & 5.02 & 0.000 & 41 & 41 & 5892 & SB1O & * \\
\hline 491 & HD & 112758 & 0.79 & 3.95 & 0.01 & 1.38 & 4.02 & 0.000 & 32 & 32 & 7413 & SB1O & $*$ \\
\hline 498 & HD & 113827 & 1.17 & -6.51 & 0.13 & 0.32 & 0.83 & 0.707 & 9 & 9 & 3568 & CST & \\
\hline $505 \mathrm{~A}$ & HD & 115404 & 0.92 & 7.51 & 0.08 & 0.25 & 0.81 & 0.817 & 14 & 14 & 3244 & CST & \\
\hline 509 & HD & 116495 & 1.33 & -39.18 & 0.12 & 0.44 & 1.07 & 0.338 & 13 & 13 & 3981 & CST & \\
\hline 511 & HD & 116858 & 0.93 & -12.61 & 0.13 & 0.43 & 1.08 & 0.325 & 11 & 11 & 2956 & CST & \\
\hline 2102 & HD & 117936 & 0.80 & -6.00 & 0.15 & 0.41 & 1.26 & 0.136 & 8 & 8 & 2958 & CST & \\
\hline 517 & HD & 118100 & 1.18 & -22.47 & 0.11 & 0.48 & 1.15 & 0.186 & 18 & 18 & 4012 & CST & \\
\hline 1176 & HD & 119291 & 1.19 & -43.17 & 0.13 & 0.23 & 0.62 & 0.917 & 8 & 8 & 2903 & CST & \\
\hline 521.1 & HD & 118926 & 1.39 & 27.27 & 0.20 & 0.64 & 1.33 & 0.071 & 10 & 10 & 4189 & CST & \\
\hline 523 & $\mathrm{BD}$ & +392675 & 1.10 & 1.24 & 0.13 & 0.34 & 0.93 & 0.542 & 8 & 8 & 2905 & CST & \\
\hline $528 \mathrm{~A}$ & HD & 120476 & 1.12 & -20.18 & 0.15 & 0.36 & 1.04 & 0.375 & 6 & 6 & 5577 & CST & \\
\hline 529 & HD & 120467 & 1.27 & -38.34 & 0.13 & 0.27 & 0.78 & 0.732 & 7 & 7 & 4008 & CST & \\
\hline 542.2 & HD & 125354 & 1.30 & 11.55 & 0.51 & 2.44 & 5.76 & 0.000 & 23 & 23 & 6151 & SB1O & $*$ \\
\hline 544 A & HD & 125455 & 0.84 & -9.93 & 0.10 & 0.21 & 0.65 & 0.929 & 10 & 10 & 3282 & CST & \\
\hline 546 & $\mathrm{BD}$ & +302512 & 1.26 & -37.18 & 0.08 & 0.30 & 0.89 & 0.699 & 17 & 17 & 3688 & CST & \\
\hline 554 & HD & 127506 & 1.13 & -18.69 & 0.07 & 0.26 & 0.76 & 0.946 & 24 & 24 & 5893 & $\mathrm{CSTO}^{3}$ & * \\
\hline 556 & HD & 128165 & 0.99 & 11.46 & 0.08 & 0.22 & 0.76 & 0.880 & 14 & 14 & 4040 & CST & \\
\hline
\end{tabular}


Table A.1. continued.

\begin{tabular}{|c|c|c|c|c|c|c|c|c|c|c|c|c|c|}
\hline 561 & $\mathrm{BD}$ & +272411 & 0.80 & -77.89 & 0.12 & 0.35 & 0.88 & 0.676 & 11 & 11 & 2904 & CST & \\
\hline 562 & $\mathrm{BD}$ & +172785 & 1.26 & 42.47 & 0.07 & 0.35 & 0.93 & 0.720 & 34 & 34 & 5721 & CST & \\
\hline 563.3 & HD & 130871 & 0.97 & -32.32 & 0.11 & 0.25 & 0.68 & 0.916 & 11 & 11 & 3291 & CST & \\
\hline 567 & HD & 131511 & 0.84 & -31.42 & 0.04 & 11.19 & 38.02 & 0.000 & 82 & 82 & 6669 & SB1O & + \\
\hline 569.1 & HD & 132142 & 0.79 & -14.59 & 0.09 & 0.28 & 0.87 & 0.719 & 14 & 14 & 4025 & CST & \\
\hline $570 \mathrm{~A}$ & HD & 131977 & 1.10 & 26.73 & 0.05 & 0.29 & 1.00 & 0.465 & 41 & 41 & 7364 & CST & \\
\hline 573 & HD & 132950 & 1.04 & -1.73 & 0.08 & 0.36 & 0.97 & 0.563 & 21 & 21 & 7272 & CST & \\
\hline 576 & BD & +062986 & 1.30 & -84.79 & 0.12 & 0.43 & 0.80 & 0.806 & 12 & 12 & 5092 & CST & \\
\hline 579 & $\mathrm{BD}$ & +252874 & 1.36 & -69.43 & 0.09 & 0.52 & 1.17 & 0.100 & 32 & 32 & 5500 & CST & \\
\hline 1189 & $\mathrm{BD}$ & +242824 & 1.06 & -53.64 & 0.32 & 1.33 & 3.63 & 0.000 & 17 & 17 & 5161 & SB1 & \\
\hline 579.3 & HD & 134985 & 0.78 & -61.49 & 0.14 & 0.45 & 1.10 & 0.290 & 10 & 10 & 3689 & CST & \\
\hline $580 \mathrm{~A}$ & HD & 135204 & 0.77 & -69.54 & 0.06 & 0.23 & 0.74 & 0.962 & 23 & 23 & 7337 & CST & \\
\hline 1190 & $\mathrm{BD}$ & -033746 & 1.13 & -112.42 & 0.13 & 0.22 & 0.50 & 0.992 & 11 & 11 & 4091 & CST & \\
\hline 583 & $\mathrm{BD}$ & -043873 & 1.30 & -19.10 & 0.15 & 0.32 & 0.77 & 0.783 & 8 & 8 & 2676 & CST & \\
\hline 1192 & HD & 136834 & 1.00 & -26.65 & 0.07 & 0.28 & 0.85 & 0.816 & 22 & 22 & 4892 & CST & \\
\hline 586 A & HD & 137763 & 0.81 & 7.47 & 0.20 & 21.20 & 66.80 & 0.000 & 110 & 120 & 6013 & SB2O & + \\
\hline $586 \mathrm{~B}$ & HD & 137778 & 0.90 & 7.56 & 0.07 & 0.31 & 0.98 & 0.507 & 18 & 18 & 6014 & CST & \\
\hline 591 & HD & 139323 & 0.95 & -67.15 & 0.09 & 0.13 & 0.47 & 0.992 & 10 & 10 & 5830 & CST & \\
\hline $593 \mathrm{~A}$ & HD & 139341 & 0.92 & -65.10 & 1.00 & 5.37 & 11.08 & 0.000 & 29 & 58 & 6651 & SB2 & \\
\hline 610 & HD & 144253 & 0.97 & 36.76 & 0.09 & 19.12 & 32.80 & 0.000 & 25 & 47 & 2973 & SB2O & $*$ \\
\hline 612 & HD & 144872 & 0.96 & 23.43 & 0.11 & 0.35 & 1.00 & 0.452 & 11 & 11 & 2991 & CST & \\
\hline 614 & HD & 145675 & 0.87 & -13.88 & 0.09 & 0.26 & 0.90 & 0.614 & 10 & 10 & 6291 & CST & \\
\hline $615.1 \mathrm{~A}$ & HD & 145958 & 0.77 & 18.37 & 0.11 & 0.37 & 1.01 & 0.424 & 11 & 11 & 5812 & CST & \\
\hline $615.1 \mathrm{~B}$ & & & 0.80 & 18.50 & 0.19 & 0.63 & 1.81 & 0.000 & 11 & 11 & 5812 & $\mathrm{SB} 1^{4}$ & \\
\hline 621 & HD & 147776 & 0.95 & 7.08 & 0.10 & 0.32 & 0.87 & 0.699 & 13 & 13 & 5225 & $\mathrm{CST}$ & \\
\hline 626 & HD & 148467 & 1.22 & -36.54 & 0.13 & 0.1 & 0.34 & 0.998 & 8 & 8 & 2994 & CST & \\
\hline $627 \mathrm{~A}$ & HD & 148653 & 0.86 & -31.13 & 0.10 & 0.28 & 0.85 & 0.704 & 11 & 11 & 4849 & CST & \\
\hline 631 & HD & 149661 & 0.81 & -12.95 & 0.09 & 0.18 & 0.62 & 0.952 & 11 & 11 & 3803 & CST & \\
\hline 632.1 & HD & 149957 & 1.20 & -11.16 & 0.13 & 0.27 & 0.72 & 0.824 & 8 & 8 & 2963 & CST & \\
\hline $632.2 \mathrm{~A}$ & $\mathrm{BD}$ & +76614 & 1.17 & -9.37 & 0.12 & 0.33 & 0.82 & 0.759 & 11 & 11 & 4546 & CST & \\
\hline 637.1 & HD & 151541 & 0.77 & 9.57 & 0.11 & 0.2 & 0.61 & 0.9 & 9 & 9 & 3339 & CST & \\
\hline 638 & HD & 151288 & 1.37 & -32.07 & 0.09 & 0.26 & 0.79 & 0.855 & 15 & 15 & 3619 & CST & \\
\hline 639 & HD & 151877 & 0.82 & 2.33 & 0.12 & 0.29 & 0.86 & 0.639 & 8 & 8 & 2674 & CST & \\
\hline 640 & HD & 151995 & 1.02 & -5.61 & 0.14 & 0.31 & 0.87 & 0.620 & 7 & 7 & 3033 & CST & \\
\hline $649.1 \mathrm{~A}$ & HD & 153557 & 0.99 & -6.65 & 0.09 & & 1.02 & 0.404 & 15 & 15 & 4847 & CST & \\
\hline $649.1 \mathrm{C}$ & HD & 153525 & 1.00 & -7.15 & 0.09 & 0.27 & 0.83 & 0.790 & 15 & 15 & 4847 & CST & \\
\hline 650 & HD & 153631 & 0.63 & 83.21 & 0.09 & 4.10 & 11.36 & 0.000 & 38 & 38 & 5246 & SB1O & + \\
\hline 653 & HD & 154363 & 1.16 & 34.02 & 0.08 & 0.30 & 0.86 & 0.779 & 18 & 18 & 6307 & CST & \\
\hline 658 & HD & 155456 & 0.87 & -59.79 & 0.12 & 0.11 & 0.34 & 0.997 & 8 & 8 & 2655 & CST & \\
\hline 659 & HD & 155674 & 1.16 & 3.15 & 0.13 & & 0.55 & & 8 & 8 & 2643 & CST & \\
\hline $659 \mathrm{~B}$ & $\mathrm{BD}$ & +541862 & 1.26 & 2.23 & 0.15 & 0.32 & 0.77 & 0.768 & 8 & 8 & 2643 & CST & \\
\hline $663 \mathrm{~A}$ & HD & 155886 & 0.86 & 0.44 & 0.10 & 0.25 & 0.81 & 0.751 & 10 & 10 & 3273 & CST & \\
\hline $663 \mathrm{~B}$ & HD & 155885 & 0.86 & 0.10 & 0.13 & 0.40 & 1.27 & 0.113 & 10 & 10 & 3273 & CST & \\
\hline 664 & HD & 156026 & 1.16 & -0.09 & 0.08 & 0.28 & 0.93 & 0.620 & 15 & 15 & 3694 & CST & \\
\hline 673 & HD & 157881 & 1.36 & -23.89 & 0.07 & 0.26 & 0.74 & 0.958 & 22 & 22 & 4477 & CST & \\
\hline 675 & HD & 158633 & 0.76 & -38.56 & 0.08 & 0.28 & 0.87 & 0.727 & 16 & 16 & 4821 & CST & \\
\hline 688 & HD & 160346 & 0.96 & 21.68 & 0.05 & 4.27 & 14.16 & 0.000 & 38 & 38 & 4436 & SB1O & + \\
\hline 689 & HD & 160964 & 1.10 & -24.41 & 0.12 & 0.36 & 1.02 & 0.410 & 9 & 9 & 2561 & $\mathrm{CST}$ & \\
\hline 692.1 & HD & 161198 & 0.77 & 23.88 & 21.35 & 6.23 & 18.63 & 0.000 & 105 & 105 & 4369 & $\mathrm{SB}_{10} \mathrm{O}^{5}$ & \\
\hline 697 & $\mathrm{BD}$ & +213245 & 0.95 & -13.14 & 0.17 & 0.47 & 1.29 & 0.114 & 8 & 8 & 2618 & CST & \\
\hline 698 & $\mathrm{BD}$ & +183497 & 1.18 & -29.78 & 0.17 & 0.48 & 1.24 & 0.152 & 8 & 8 & 2226 & CST & \\
\hline 700.2 & HD & 164922 & 0.80 & 20.14 & 0.07 & 0.22 & 0.75 & 0.911 & 17 & 17 & 3717 & $\mathrm{CST}$ & \\
\hline $702 \mathrm{~A}$ & HD & 165341 & 0.86 & -9.73 & 0.52 & 2.16 & 7.03 & 0.000 & 17 & 17 & 5911 & $\mathrm{SB} 1^{6}$ & \\
\hline 706 & HD & 166620 & 0.87 & -19.47 & 0.07 & 0.22 & 0.74 & 0.911 & 16 & 16 & 4092 & CST & \\
\hline
\end{tabular}


Table A.1. continued.

\begin{tabular}{|c|c|c|c|c|c|c|c|c|c|c|c|c|c|}
\hline 715 & HD & 170493 & 1.10 & -55.20 & 0.09 & 0.24 & 0.76 & 0.836 & 11 & 11 & 2617 & CST & \\
\hline 718 & HD & 171314 & 1.12 & 38.25 & 0.10 & 0.20 & 0.58 & 0.971 & 11 & 11 & 2612 & CST & \\
\hline 719 & HD & 234677 & 1.22 & -25.53 & 0.08 & 19.30 & 48.35 & 0.000 & 47 & 88 & 7096 & SB2O & + \\
\hline 722.1 & HD & 172393 & 0.82 & 32.24 & 0.11 & 0.28 & 0.80 & 0.764 & 10 & 10 & 2620 & CST & \\
\hline 725.1 & HD & 173701 & 0.84 & -45.55 & 0.07 & 0.31 & 1.05 & 0.352 & 18 & 18 & 5204 & CST & \\
\hline 727 & HD & 174080 & 1.08 & -7.17 & 0.09 & 0.17 & 0.55 & 0.986 & 12 & 12 & 3020 & CST & \\
\hline 747.2 & $\mathrm{BD}$ & +33 3339 & 1.25 & 8.78 & 0.64 & 2.99 & 3.34 & 0.000 & 22 & 38 & 5561 & SB2 & \\
\hline 753 & BD & +87183 & 1.06 & -5.74 & 0.14 & 0.29 & 0.73 & 0.843 & 9 & 9 & 2569 & CST & \\
\hline 758 & HD & 182488 & 0.81 & -21.56 & 0.06 & 0.20 & 0.69 & 0.971 & 20 & 20 & 3026 & $\mathrm{CST}$ & \\
\hline 1237 & HD & 183255 & 0.93 & -64.95 & 0.11 & 10.65 & 23.46 & 0.000 & 48 & 96 & 2259 & SB2O & + \\
\hline $761 \mathrm{~A}$ & BD & +123917 & 1.10 & -18.35 & 0.13 & 0.38 & 1.01 & 0.415 & 9 & 9 & 2642 & CST & \\
\hline 762.1 & HD & 184467 & 0.87 & 11.63 & 0.08 & 7.14 & 7.43 & 0.000 & 18 & 36 & 4105 & SB2O & + \\
\hline 764 & HD & 185144 & 0.80 & 26.64 & 0.09 & 0.35 & 1.14 & 0.202 & 14 & 14 & 4426 & CST & \\
\hline $764.1 \mathrm{~A}$ & HD & 184860 & 1.01 & 63.19 & 0.23 & 0.75 & 2.08 & 0.000 & 11 & 11 & 5564 & SB1 & \\
\hline 764.1B & & & 1.20 & 64.68 & 0.49 & 0.85 & 1.92 & 0.027 & 3 & 3 & 3698 & CST & \\
\hline 765.2 & HD & 186922 & 0.88 & -5.21 & 0.80 & 5.81 & 6.95 & 0.000 & 53 & 103 & 5516 & $\mathrm{SB}_{2} \mathrm{O}^{7}$ & \\
\hline 773.2 & HD & 189087 & 0.80 & -29.68 & 0.06 & 0.24 & 0.81 & 0.873 & 21 & 21 & 5557 & CST & \\
\hline 775 & HD & 190007 & 1.12 & -30.51 & 0.10 & 0.32 & 1.06 & 0.350 & 10 & 10 & 3272 & CST & \\
\hline 778 & HD & 190404 & 0.82 & -2.55 & 0.06 & 0.30 & 0.90 & 0.777 & 30 & 30 & 7337 & CST & \\
\hline 779.1 & HD & 190470 & 0.91 & -7.33 & 0.09 & 0.12 & 0.41 & 0.999 & 12 & 12 & 3023 & CST & \\
\hline 781.2 & HD & 191285 & 1.12 & -18.55 & 0.14 & 0.44 & 1.00 & 0.449 & 10 & 10 & 3008 & CST & \\
\hline $783.2 \mathrm{~A}$ & HD & 191785 & 0.85 & -49.52 & 0.08 & 0.29 & 0.94 & 0.583 & 14 & 14 & 3369 & CST & \\
\hline 791.3 & BD & +333936 & 1.13 & -27.05 & 0.11 & 0.15 & 0.44 & 0.995 & 10 & 10 & 3008 & CST & \\
\hline 795 & HD & 196795 & 1.22 & -40.86 & 0.14 & 2.27 & 6.49 & 0.000 & 99 & 99 & 7660 & SB1O & + \\
\hline $1255 \mathrm{D}$ & HD & 199476 & 0.71 & -30.23 & 0.13 & 0.36 & 1.02 & 0.397 & 8 & 8 & 1772 & CST & \\
\hline 808.2 & HD & 198550 & 1.06 & -8.48 & 0.10 & 0.44 & 1.42 & 0.005 & 21 & 21 & 5127 & SB1? & \\
\hline 1259 & BD & +124499 & 1.05 & -41.03 & 0.06 & 1.19 & 3.57 & 0.000 & 29 & 29 & 5177 & SB1O & $*$ \\
\hline 816.1A & HD & 200560 & 0.97 & -14.11 & 0.09 & 0.21 & 0.69 & 0.920 & 12 & 12 & 2961 & CST & \\
\hline 818 & HD & 200779 & 1.22 & -66.81 & 0.09 & 0.31 & 0.94 & 0.584 & 14 & 14 & 3340 & CST & \\
\hline 819 A & HD & 200968 & 0.90 & -32.72 & 0.09 & 0.15 & 0.48 & 0.996 & 12 & 12 & 2967 & CST & \\
\hline $820 \mathrm{~A}$ & HD & 201091 & 1.17 & -65.82 & 0.06 & 0.34 & 1.11 & 0.179 & 30 & 30 & 6226 & CST & \\
\hline 820 & HD & 201092 & 1.37 & -64.67 & 0.06 & 0.30 & 0.91 & 0.725 & 29 & 29 & 6226 & CST & \\
\hline 824 & HD & 202575 & 1.02 & -18.24 & 0.09 & 0.27 & 0.83 & 0.760 & 13 & 13 & 2964 & CST & \\
\hline 825.3 & HD & 202751 & 0.99 & -27.65 & 0.09 & 0.20 & 0.65 & 0.957 & 13 & 13 & 3349 & CST & \\
\hline 828.4 & HD & 204417 & 0.86 & -14.63 & 0.09 & 0.33 & 0.99 & 0.476 & 14 & 14 & 3639 & CST & \\
\hline 836.8 & $\mathrm{BD}$ & +404631 & 1.34 & 9.75 & 0.13 & 0.21 & 0.53 & 0.973 & 9 & 9 & 2966 & CST & \\
\hline $838.1 \mathrm{~A}$ & HD & 207491 & 1.04 & -11.22 & 0.10 & 0.21 & 0.66 & 0.933 & 11 & 11 & 3338 & CST & \\
\hline 838.2 & HD & 207795 & 0.83 & -29.29 & 0.10 & 0.32 & 0.94 & 0.569 & 11 & 11 & 3342 & CST & \\
\hline 840 & HD & 208313 & 0.92 & -13.42 & 0.07 & 0.21 & 0.72 & 0.934 & 16 & 16 & 2976 & CST & \\
\hline 850 & HD & 210667 & 0.82 & -19.55 & 0.07 & 0.18 & 0.64 & 0.982 & 17 & 17 & 2976 & CST & \\
\hline 851.4 & $\mathrm{BD}$ & +562737 & 0.72 & 2.45 & 0.15 & 11.38 & 19.42 & 0.000 & 76 & 131 & 7440 & SB2O & $*$ \\
\hline 854 & BD & +671424 & 1.15 & -4.44 & 0.11 & 0.33 & 0.91 & 0.611 & 10 & 10 & 2951 & CST & \\
\hline $857.1 \mathrm{~A}$ & BD & +214747 & 1.19 & -7.15 & 0.10 & 0.32 & 0.96 & 0.516 & 11 & 11 & 4063 & CST & \\
\hline $867.1 \mathrm{~A}$ & HD & 214615 & 0.63 & -12.57 & 0.11 & 0.67 & 1.76 & 0.000 & 35 & 35 & 7389 & SB1O & $*$ \\
\hline 870 & $\mathrm{BD}$ & +424471 & 1.11 & -32.64 & 0.15 & 6.17 & 15.98 & 0.000 & 25 & 25 & 1392 & SB1O & $*$ \\
\hline $1272 \mathrm{~A}$ & $\mathrm{BD}$ & +104812 & 1.13 & -1.60 & 0.12 & 0.24 & 0.63 & 0.941 & 10 & 10 & 2583 & CST & \\
\hline 871.2 & HD & 215704 & 0.80 & -51.46 & 0.10 & 0.27 & 0.83 & 0.715 & 10 & 10 & 2912 & CST & \\
\hline 886 & HD & 217580 & 0.95 & -44.19 & 0.04 & 1.78 & 5.75 & 0.000 & 25 & 25 & 2891 & SB1O & + \\
\hline 892 & HD & 219134 & 1.00 & -18.58 & 0.07 & 0.26 & 0.92 & 0.633 & 16 & 16 & 4057 & CST & \\
\hline 893.2B & HD & 219430 & 1.05 & -24.29 & 0.34 & 0.05 & 0.10 & 0.919 & 1 & 1 & 0 & $?$ & \\
\hline 894.4 & HD & 220182 & 0.80 & 3.32 & 0.06 & 0.23 & 0.78 & 0.923 & 23 & 23 & 4435 & CST & \\
\hline 894.5 & HD & 220339 & 0.89 & 33.77 & 0.10 & 0.22 & 0.69 & 0.898 & 10 & 10 & 2888 & CST & \\
\hline 895.4 & HD & 221354 & 0.83 & -25.02 & 0.09 & 0.14 & 0.46 & 0.993 & 10 & 10 & 2886 & CST & \\
\hline $904.1 \mathrm{~A}$ & HD & 222474 & 1.11 & -19.24 & 0.12 & 0.44 & 1.33 & 0.046 & 14 & 14 & 5135 & CST & \\
\hline 907.1 & BD & -136464 & 1.26 & -9.04 & 0.45 & 0.45 & 1.00 & 9.999 & 1 & 1 & 0 & $?$ & \\
\hline 908.1 & $\mathrm{BD}$ & +295007 & 1.26 & -3.92 & 0.11 & 0.27 & 0.75 & 0.831 & 10 & 10 & 2887 & CST & \\
\hline $909 \mathrm{~A}$ & HD & 223778 & 0.98 & 4.54 & 0.37 & 22.54 & 29.97 & 0.000 & 7 & 13 & 2853 & SB2O & + \\
\hline 909.1 & HD & 223782 & 1.08 & -29.26 & 0.12 & 0.29 & 0.73 & 0.874 & 11 & 11 & 5048 & CST & \\
\hline
\end{tabular}


J.-L. Halbwachs et al.: Multiplicity among solar-type stars. IV.

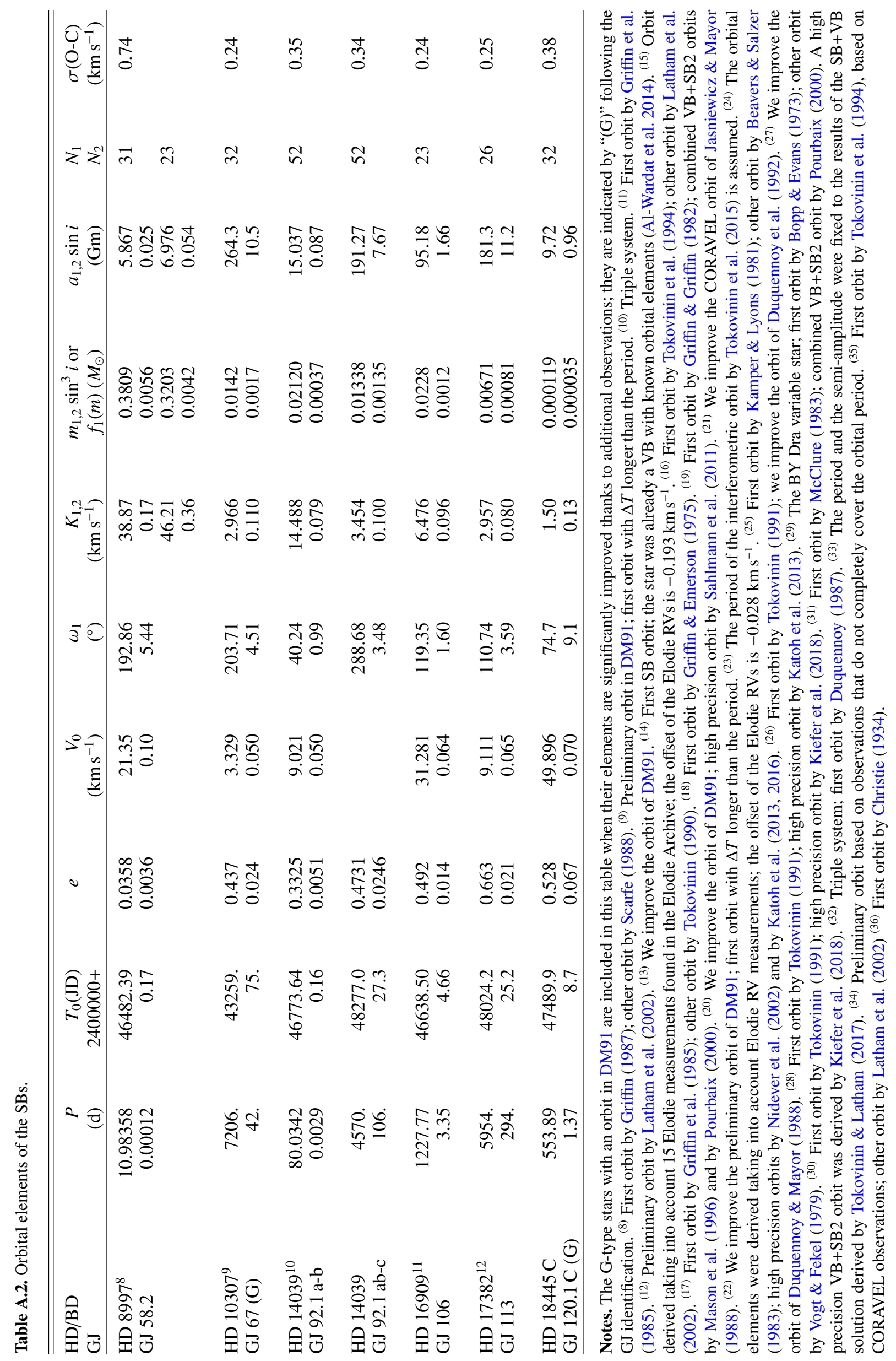




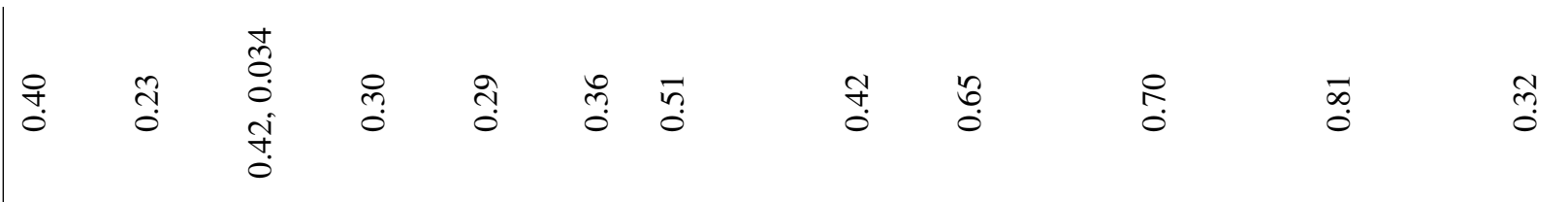

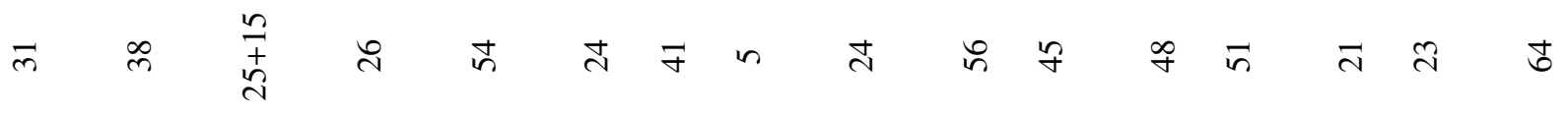

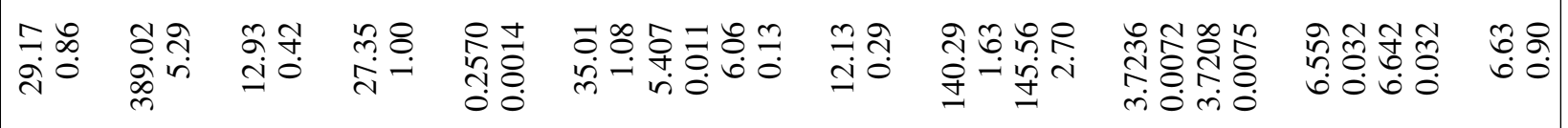

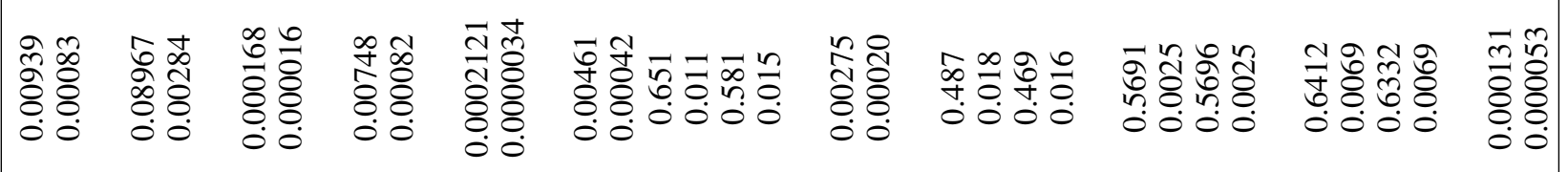
奂先 号

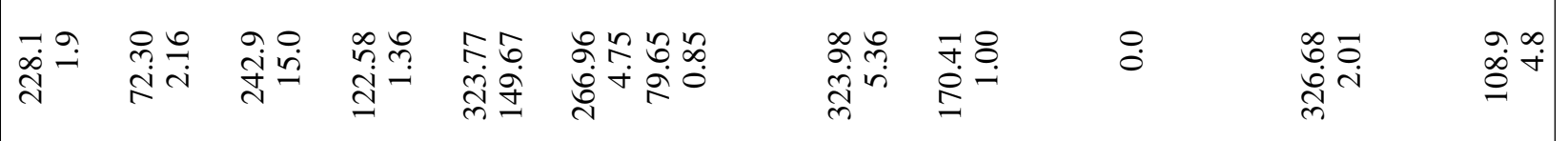

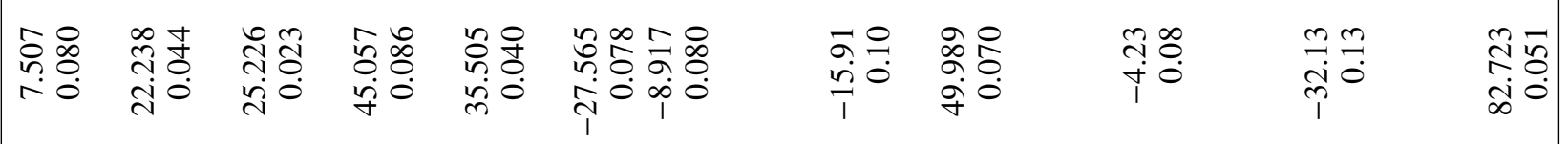

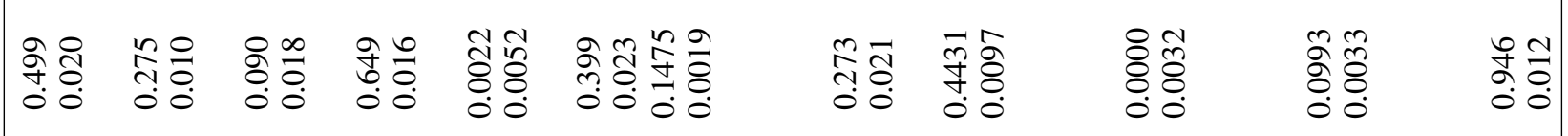

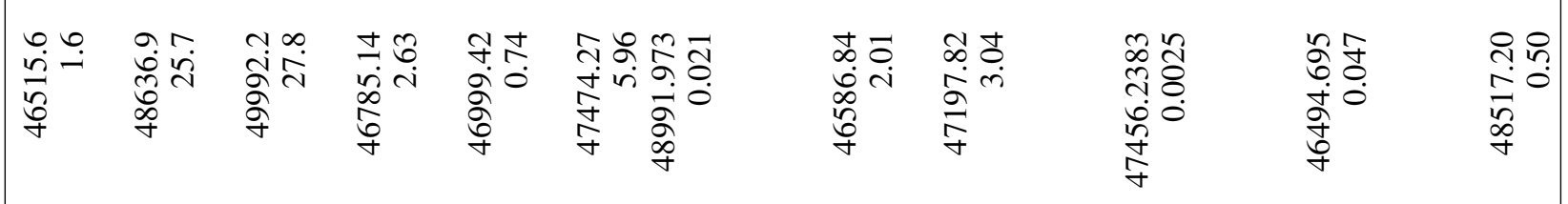

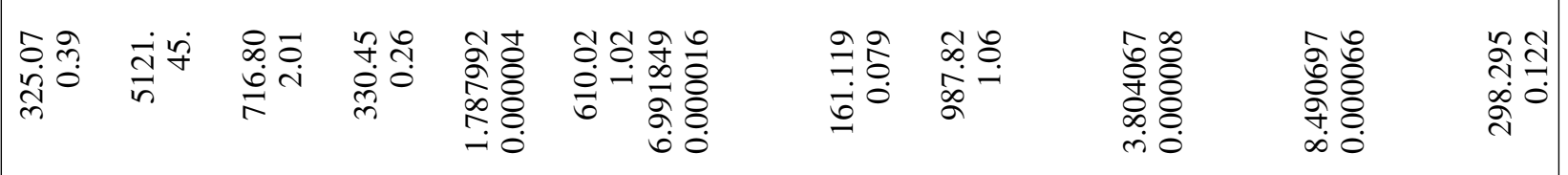


J.-L. Halbwachs et al.: Multiplicity among solar-type stars. IV.

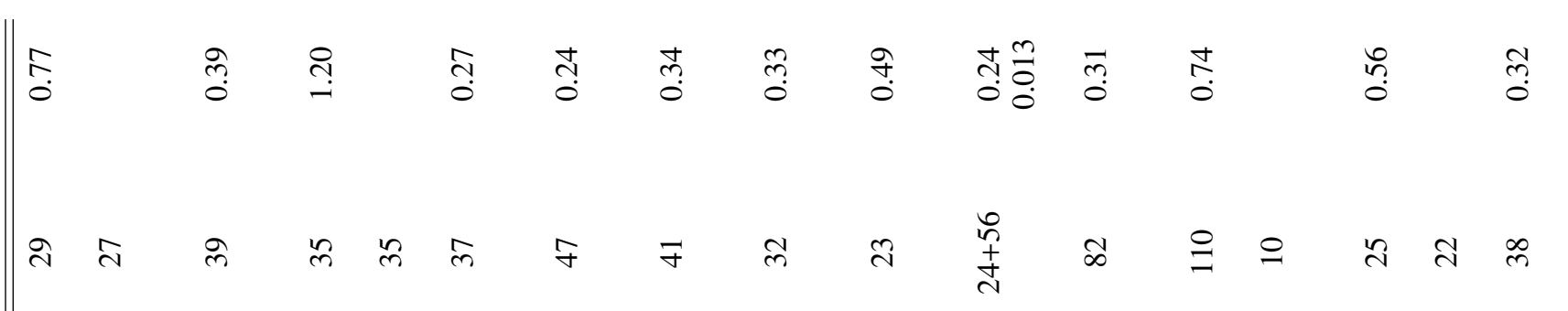

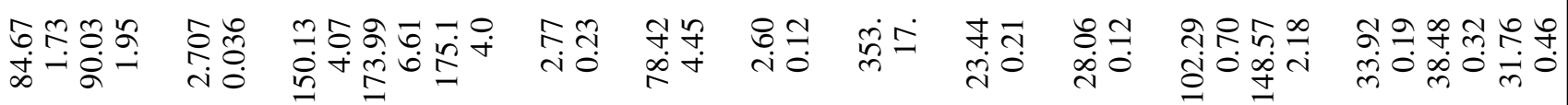

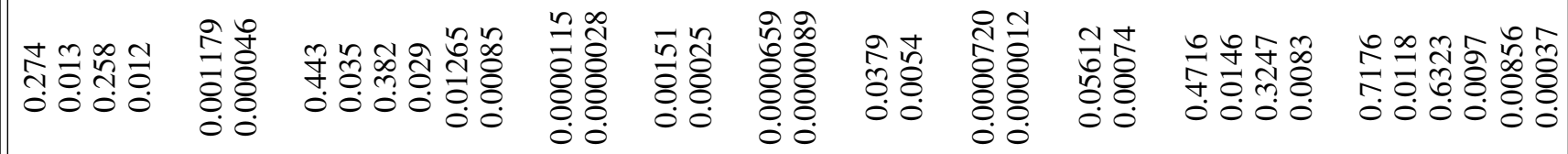

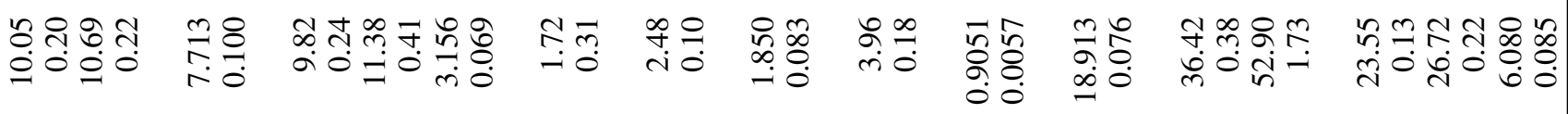

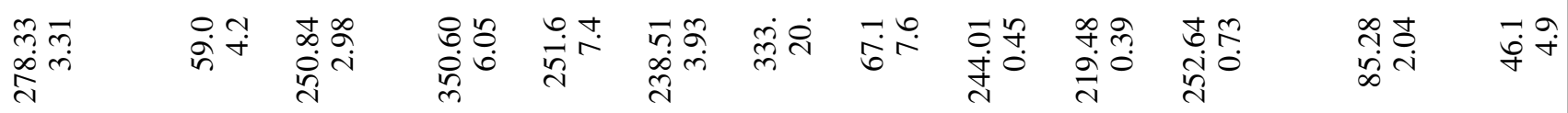

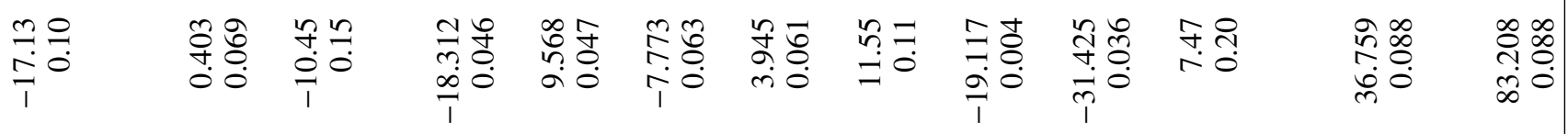

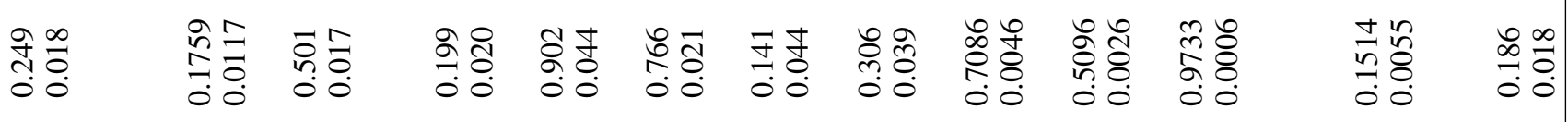

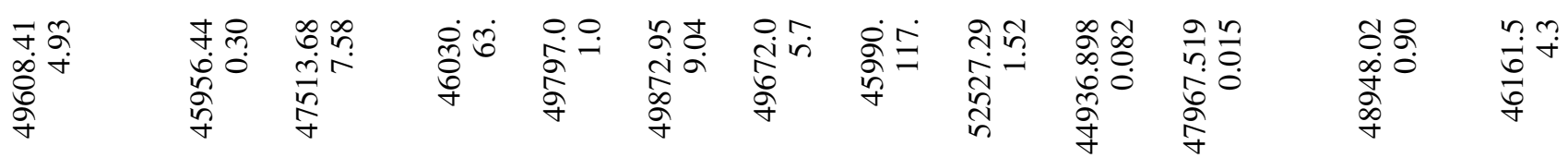

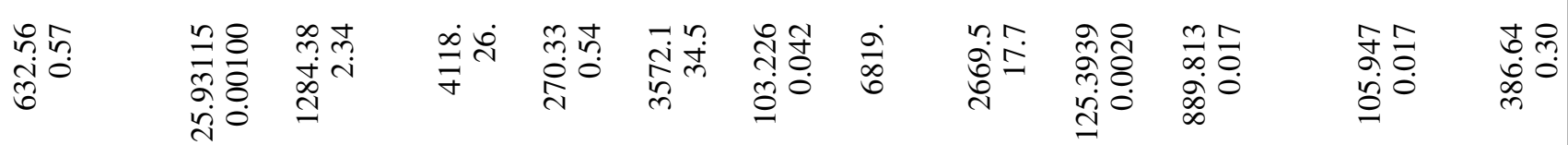

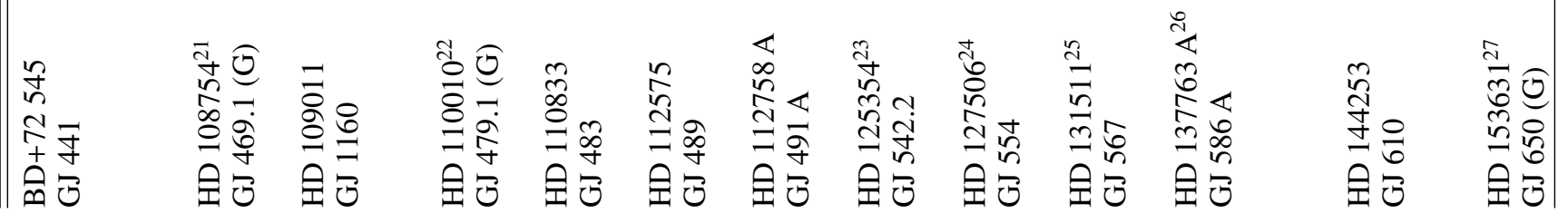




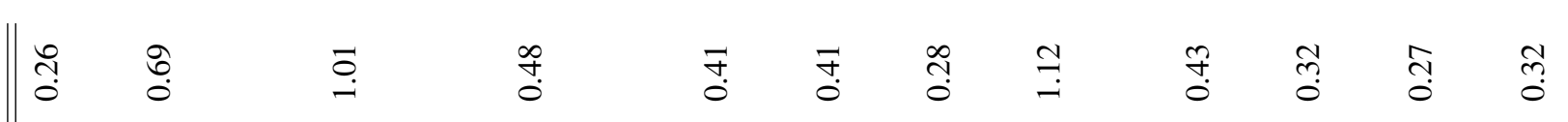

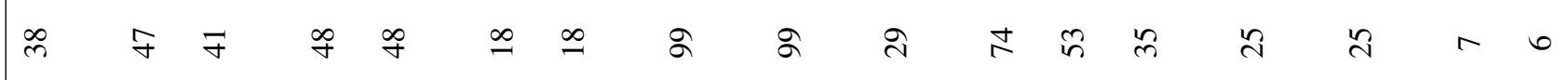

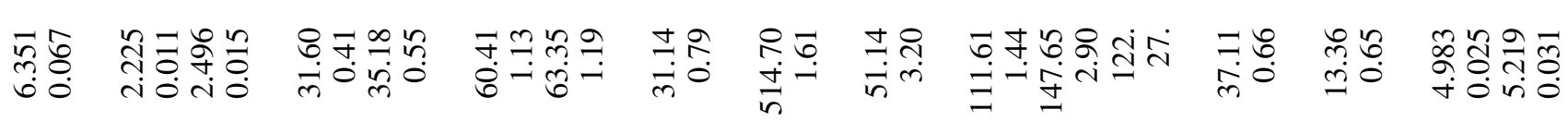

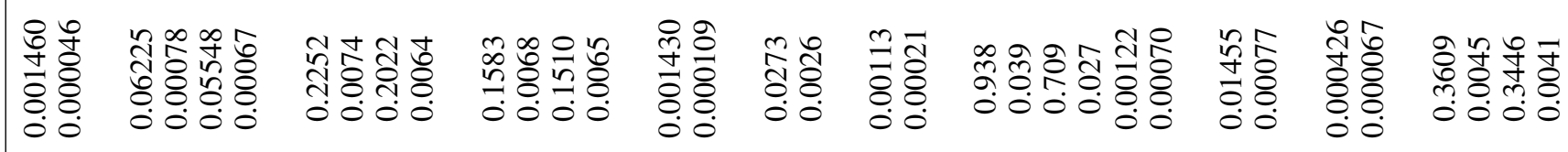

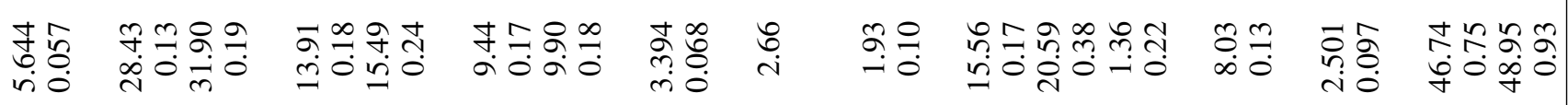

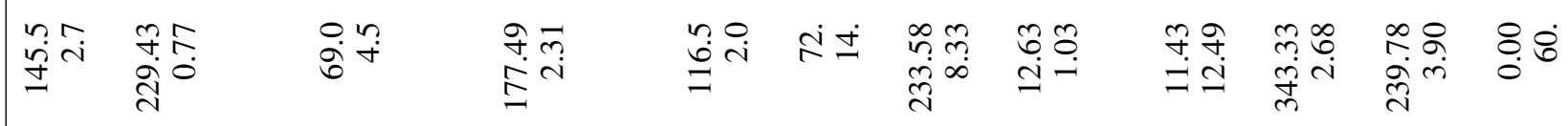

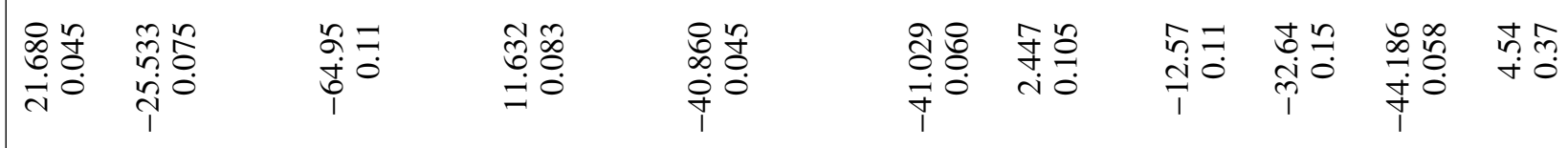

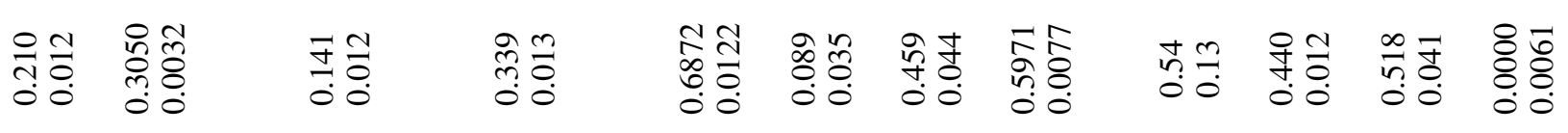

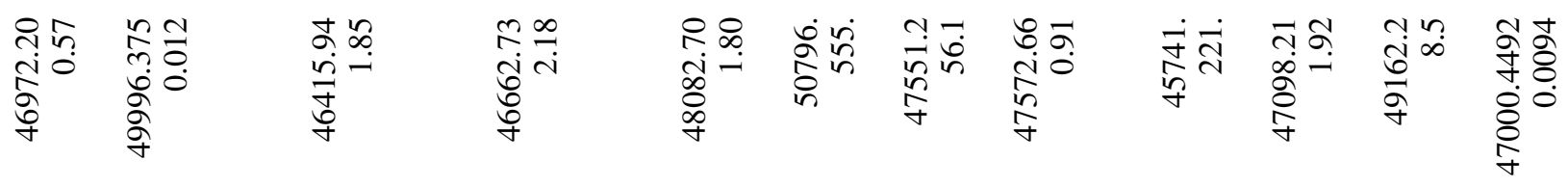

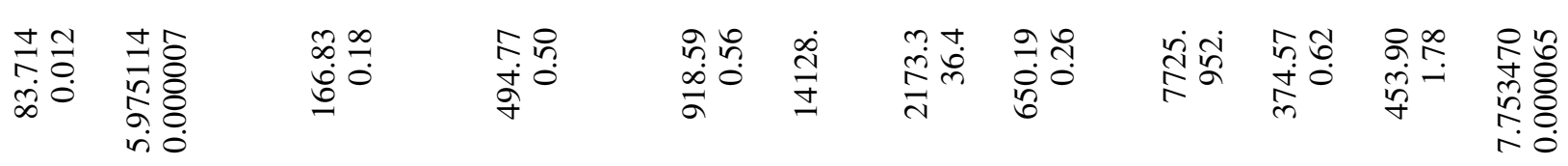

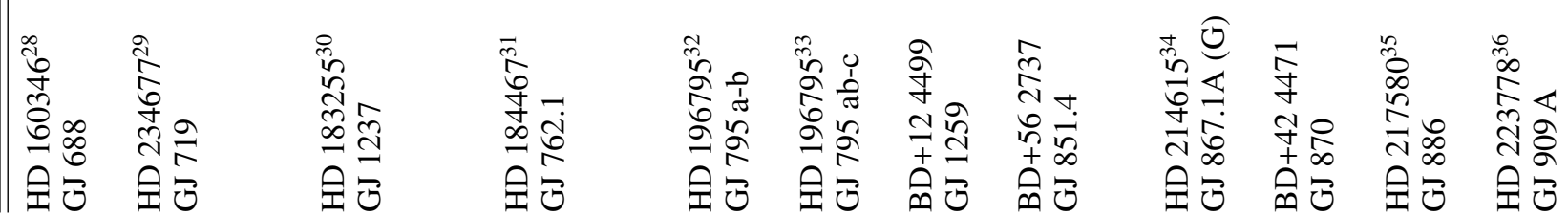

